\title{
Research Paper \\ Investigating the psychometric properties of english vocabulary size test using network data analysis
}

\author{
Nadia Soltani ${ }^{1}$, Shahram Vahedi ${ }^{2}$, Mansour Bayrami ${ }^{3}$, Mohammad Hosein Zarghami ${ }^{4}$ \\ 1. Ph.D Student of Educational Psychology, Department of Educational Science, University of Tabriz, Tabriz, Iran. \\ 2. Professor, Department of Educational Sciences, University of Tabriz, Tabriz, Iran. \\ 3. Professor, Department of Psychology, University of Tabriz, Tabriz, Iran. \\ 4. Assistant Professor, Behavioral Sciences Research Center, Baqiyatallah University of Medical Sciences, Tehran, Iran.
}

Citation: Soltani, N., Vahedi, Sh., Bayrami, M., Zarghami, M.H. Investigating the psychometric properties of english vocabulary size test using network data analysis. J of Psychological Science. 2021; 20(103): 1131-1146.

URL: https://psychologicalscience.ir/article-1-1131-fa.html
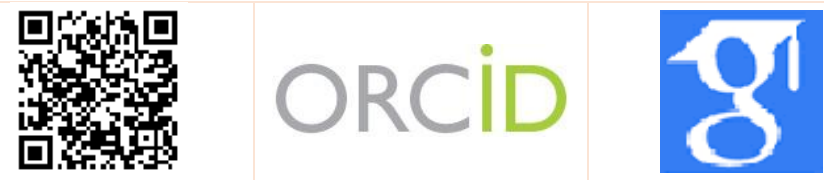

\section{A R T I C L E I N F O A B S T R A C T}

Keywords:

Network Theory,

Question analysis,

Network parameters,

Bayesian Network
Background: Network science as a new field in psychological measurement provides a good platform for test analysis, but in Iran, research on the analysis of test questions using network data analysis has been neglected.

Aims: The aim of this study was to introduce network data analysis as a psychometric-mathematical technique and its use in the questionnaire analysis process.

Methods: This research is descriptive-analytical, the statistical population of all language learners was the top ten language teaching institutes in Tehran in 2020, from which 1556 language learners were selected by convenience sampling method and answering the English vocabulary size test (Nation and Waring, 1997). Data analysis was performed by qgraph software package under R software.

Results: The graph obtained from the communication network of questions based on the Fruchterman-Ringold algorithm was plotted, the parent-child relationship of the questions was determined based on the Bayesian network, and the descriptive features of the test and the indicators of network centrality were extracted.

Conclusion: Introducing the technique of analyzing network data and using it for questions analysis process is one of the achievements of this article. Using the advantages of network science such as the ability to simplify, manage, store and collect high-volume data and analyze test questions based on the map and indicators that are fully consistent with it, we can understand the internal relationship between different test questions, and by considering the importance of the questions in the network structure of the net relationship between the questions, it is possible to improve the testing methods. Similar studies and researches are proposed to compare the results of network data analysis with psychometric properties obtained based on conventional and classical methods.
Received: 30 Jan 2021

Accepted: 28 Feb 2021

Available: 23 Sep 2021 


\section{Monthly Journal of Psychological Science}

\section{Extended Abstract}

\section{Introduction}

The use of network data analysis in the field of psychology and psychometrics is considered to be the latest methodology. Network methodology makes it possible to study several objectives simultaneously. Under the best of conditions, the measurement model provides an integrated texture that meets the requirements for testing at the same time (Araghi, Taheri, joz Ramazani, Abas pour\& Zarghami, 2017). The ability to integrate different variables through network data analysis can be used in test analysis and extraction of test indicators. Two reasons have led to the consideration of the network approach in the field of psychometric: a) in recent years, models and theories about latent variables have prevailed b) Unlike latent models, the network perspective has helped to develop dynamic systems (Borsboom, 2008). The purpose of question analysis and determination of test-construction indicators is to identify inappropriate questions and correct them, and finally to develop a measurement tool. In the network method, the question analysis is performed based on the map and parameters that correspond exactly to it, which is the result of the internal relationship between different test questions (Dörnyei, 2014). Here, network nodes refer to the test questions being studied, and the relationship between them is determined by interface lines called edges (Saarinen, Cater\& Littman, 2020).

In this research, the benefits of network data analysis are used to analyze English vocabulary size test. Today, the importance and use of English in professional and educational affairs in the international arena is not hidden from anyone. Assessing language learners is an important part of teaching any foreign language. Inaccurate assessment of individuals' language knowledge can greatly affect the learning process. Therefore, designing the principles of making standardized tests can greatly guarantee the success of language teaching. The aim of this study was to introduce network data analysis as a psychometric-mathematical technique and its use in the questionnaire analysis process.

\section{Method}

This research is descriptive-analytical, the statistical population of all language learners was the top ten language teaching institutes in Tehran in 2020, from which 1556 language learners were selected by convenience sampling method and answering the English vocabulary size test (Nation and Waring, 1997). To draw the network map of vocabulary size test, Fruchterman-Ringold
Vol. 20, No. 103, Autumn(October) 2021

algorithm and qgraph software package under R software were used and based on that, network parameters were extracted. To investigate the parent-child relationship, Bayesian network were drawn based on the Hilling Climbing (HC) algorithm using bnlearn and bnviewer software packages.

\section{Results}

In this study, the Cronbach's alpha reliability coefficient for all questions (140 questions) was 0.921. Nonlinear multifactorial analysis was performed under R software. We need a correlation matrix to map the network of relationships between vocabulary test questions. Since the test questions are dual values, the tetrachoric correlation matrix was chosen. The graph obtained from the communication network of questions based on the Fruchterman-Ringold algorithm was plotted (figure 1). Each graph has its own characteristics: A) Edge thickness (meaning the lines drawn between two nodes) indicates a significant relationship between the two questions based on correlation. B) The more this connection, the thicker the edge between the two nodes, the presence of the interface line means a meaningful connection. C) Indicates the color of the edges to communicate between variables. Green edges indicate a significant positive relationship between nodes, and red edges indicate a significant negative relationship. D) Central nodes are nodes that are located in the center of the graph, peripheral nodes are nodes that are located around. F) The proximity of nodes to each other indicates a high relationship between them. The parent-child relationship of the questions was determined based on the Bayesian network (figure 2), and the descriptive features of the test and the indicators of network centrality were extracted. 


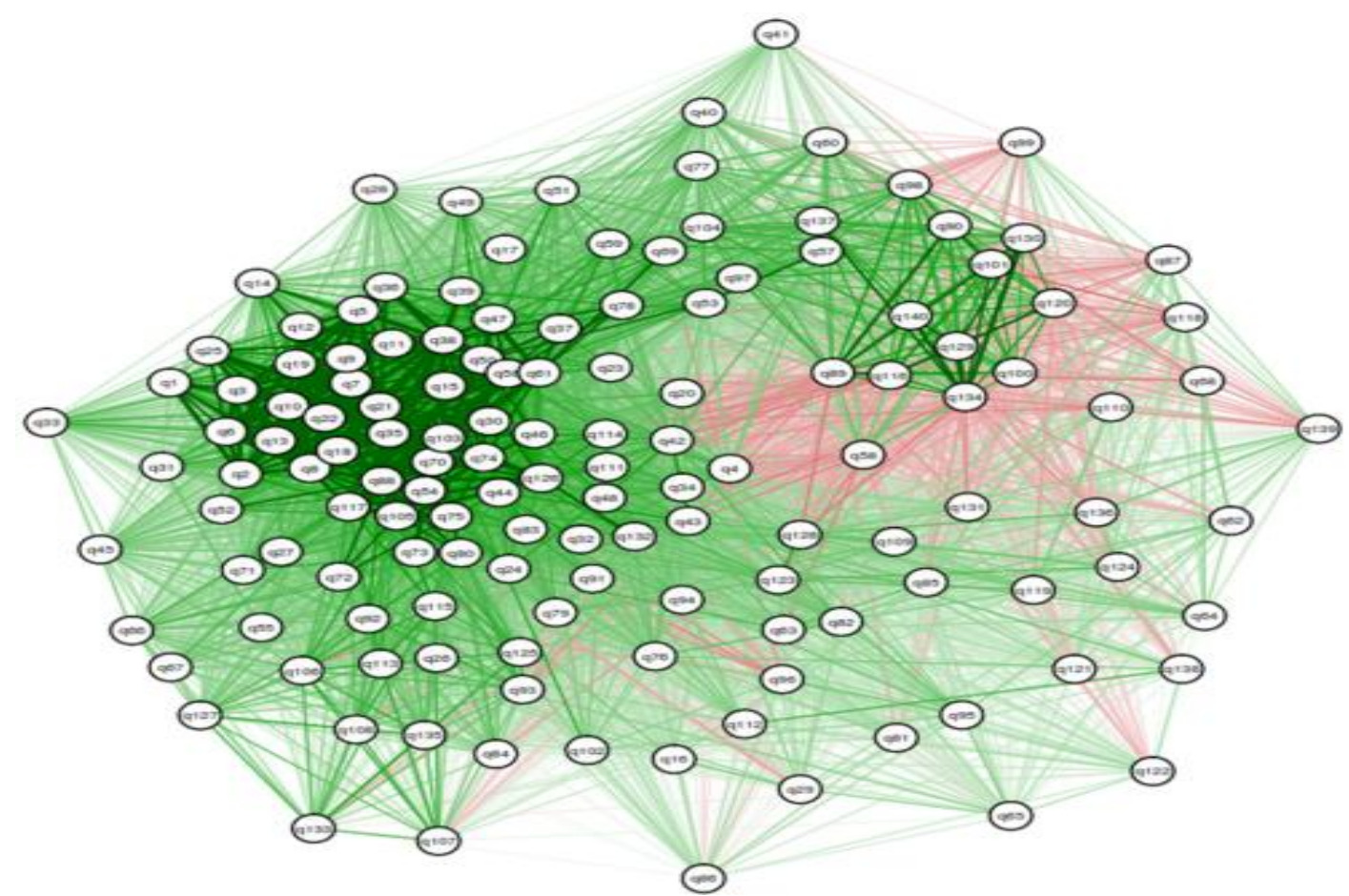

Figure 1: Network map of the relationship based on tetracoric correlation

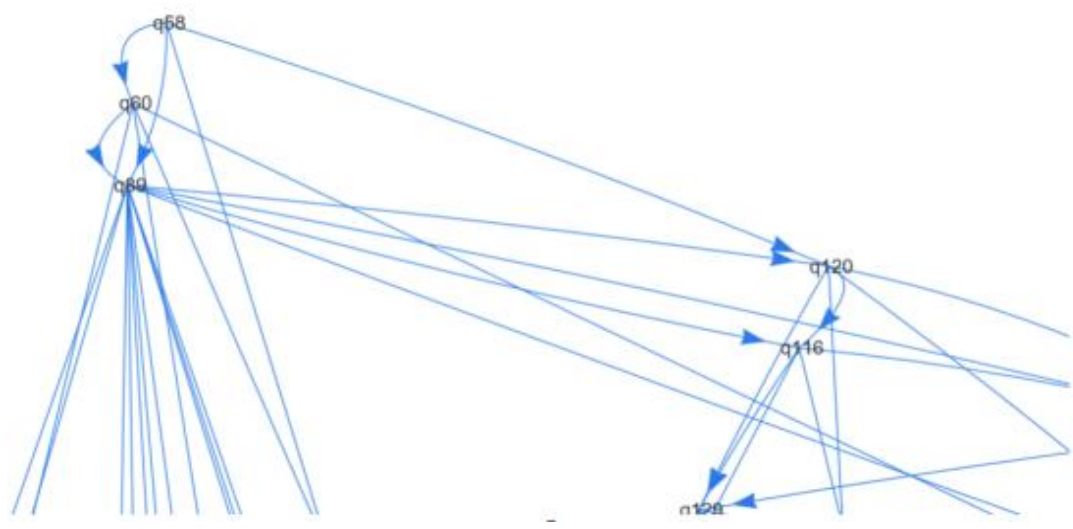

Figure 2: Bayesian network with $\mathrm{HC}$ algorithm

\section{Conclusion}

Introducing the technique of analyzing network data and using it for questions analysis process is one of the achievements of this article. The use of graph theory-based methods is faster in finding inappropriate questions, and through it, the relationship matrix between the questions can be visualized quite clearly and a lot of information can be presented together. Using the advantages of network science such as the ability to simplify, manage, store and collect high-volume data and analyze test questions based on the map and indicators that are fully consistent with it, we can understand the internal relationship between different test questions, and by considering the importance of the questions in the network structure of the net relationship between the questions, it is possible to improve the testing methods. Similar studies and researches are proposed to compare the results of network data analysis with psychometric properties obtained based on conventional and classical methods.

\section{Ethical Considerations}

Compliance with ethical guidelines: This article is ectracted from $\mathrm{PhD}$ dissertation of the first auther in the major of educational psychology from Tabriz University and the date of 


\section{Monthly Journal of Psychological Science}

Vol. 20, No. 103, Autumn(October) 2021

approval of the proposal is $11 / 06 / 2019$. Before the test, while giving the necessary explanations to the participants about the importance and purpose of the research, they were given the opportunity to ask their questions in the field of research, as well as before the test to not be forced and voluntary to participate in the research and It was also pointed out that the personal information of the volunteers was kept confidential and not used elsewhere, and in order to gain the trust and anonymity of the participants, their names and surnames were refused.
Funding: This study was conducted as a $\mathrm{PhD}$ thesis with no financial support.

Authors' contribution: The first author is the main researcher of this research. The second and third authors are the supervisors and forth auther was the advisor.

Conflict of interest: The authers declear no conflict of interest for this study.

Acknowledgments: I would like to appreciate the supervisors, advisor and the participants. 


\section{بروسى ويز حىهاى روانسنجى آزمون خزانة لغات انتليسى با استفاده از تحليل دادههاى شبكهاى}

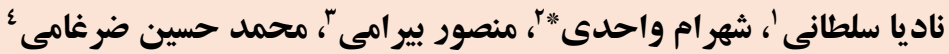

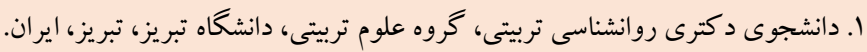

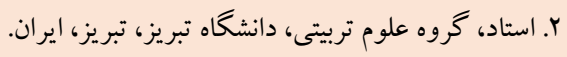

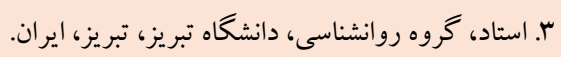

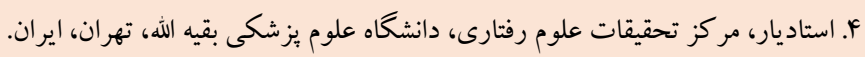

\section{جكيده}

زمينه: علم شبكه به عنوان يك حوزهُ نوين در اندازه خيرى روانشناختى بستر مناسبى را براى انجام تحليلهاى آزمونسازى فراهم مى آورد،

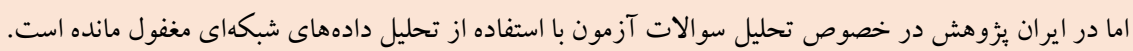

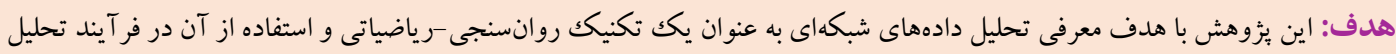
سؤالات برسشنامه انجام شد.

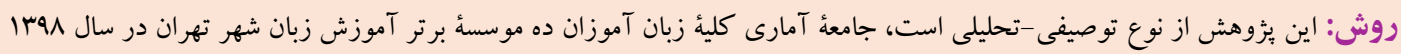

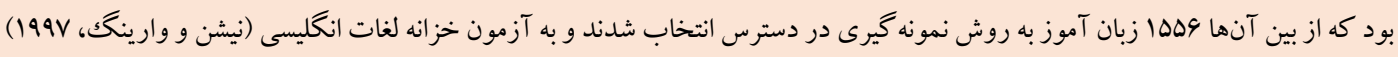

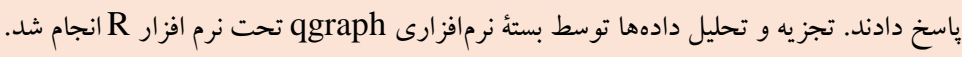

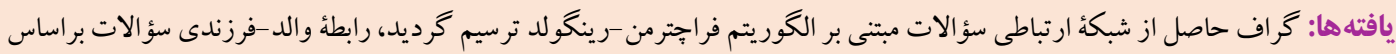

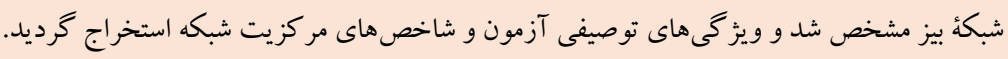

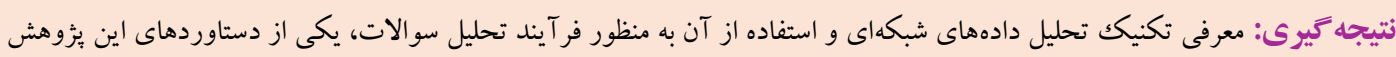

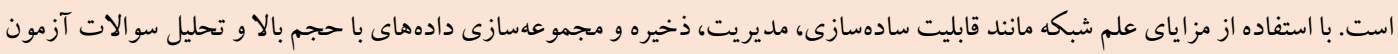

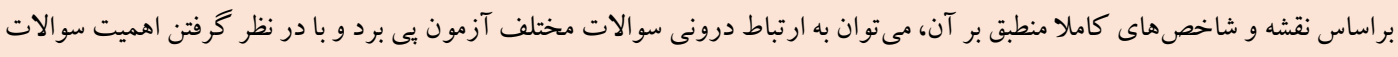

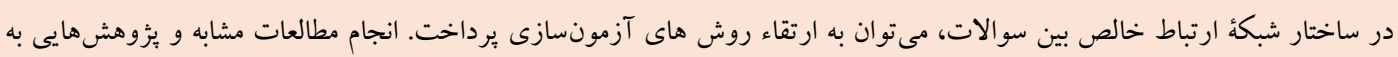

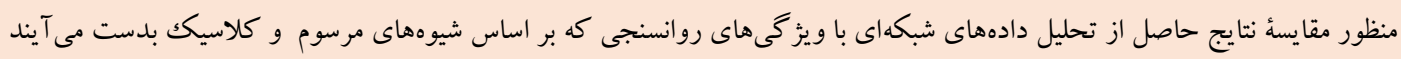
يشنهاد مى گردد.
مشخصات مقاله

كليدوازهها: نظريهُ شبكه، تحليل سوال، شاخص هاى شبكه، شبكة بيزين

دريافت شده: I |

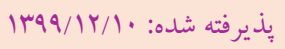

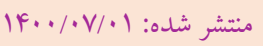

* نويسنده مسئول: شهرام واحدى، استاد، گروه علوم تربيتى، دانشخاه تبريز، تبريز، ايران. vahedi117@yahoo.com 
به استفاده از مدلهاى مختلف شبكه در حوزهُ سنجش تربيتى ببردازند، به

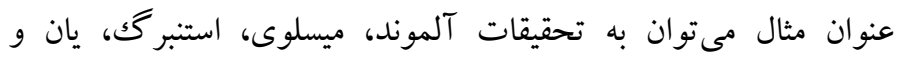

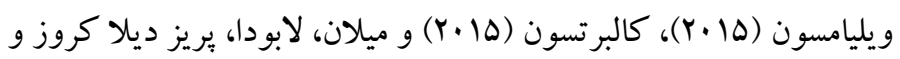

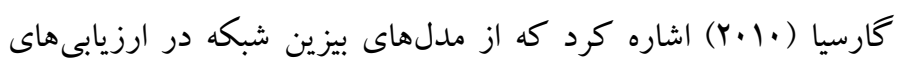
آموزشى استفاده كردهاند.

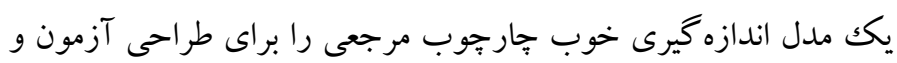

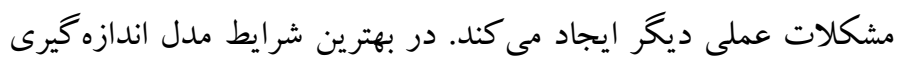

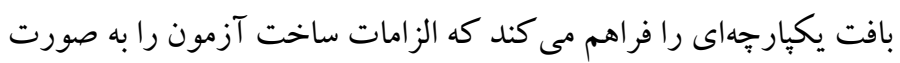

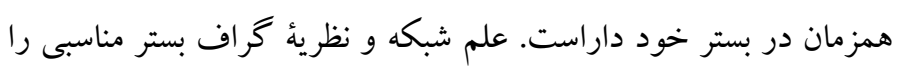

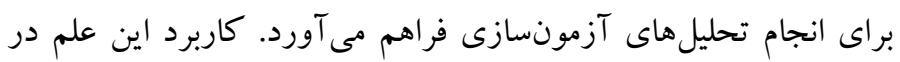

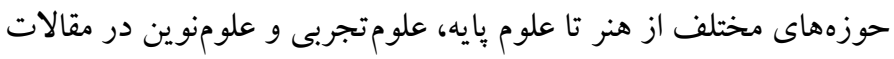

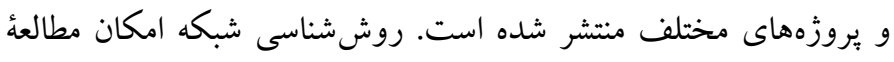

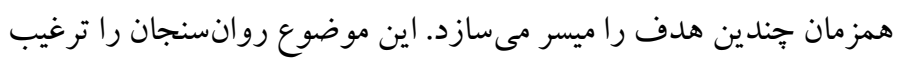

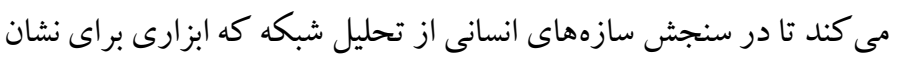
دادن عناصر يك سيستم و ارتباط درونى آن است، استفاده نمايند (عراقى،

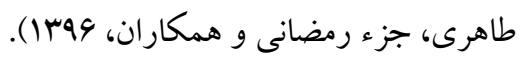

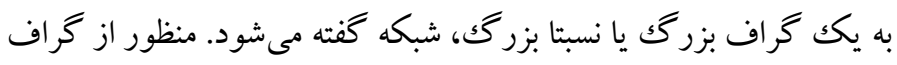

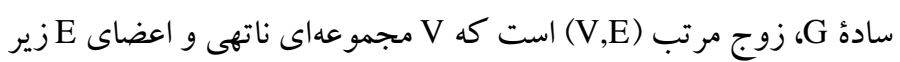

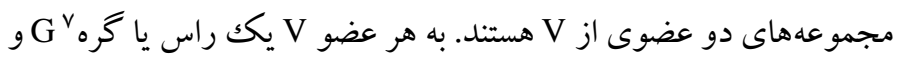

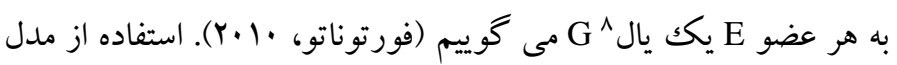

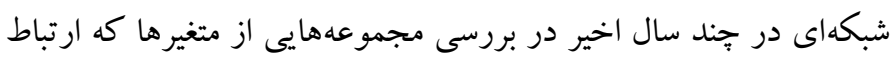

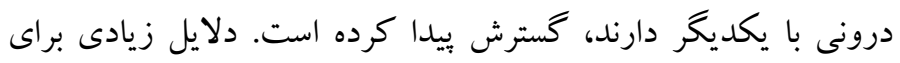

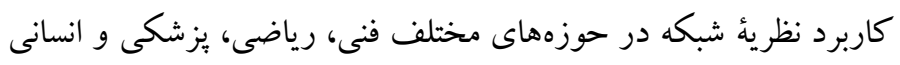

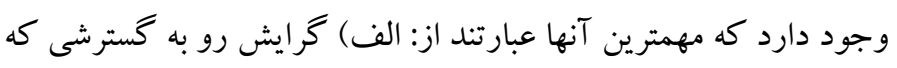
به رويكرد سيستمى در حوزهُ علم است، ب) فرار از تقليل گرايى كه ويثز اصلى علم قرن كذشته است و ج) قابليت سادهسازى، مديريت، ذخيره و

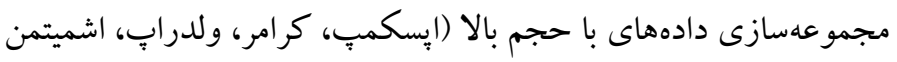

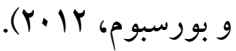

5. classic theory

${ }^{6}$. item response theory

7 . node

. edge
مقلفمه

يكى از مسايل اصلى آزمونسازى' روانى بررسى نظرى و تجربى'

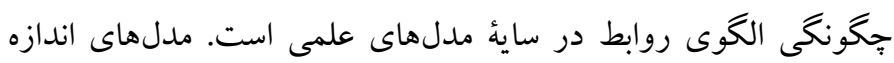

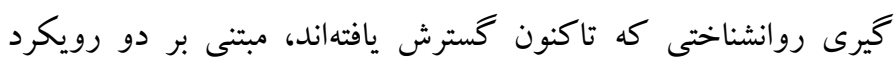

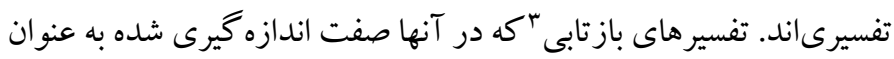

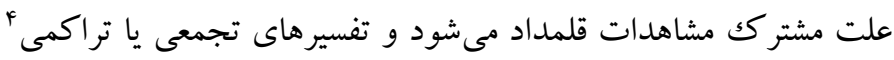

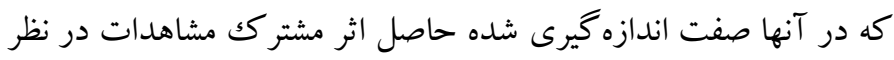

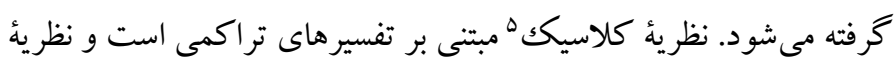

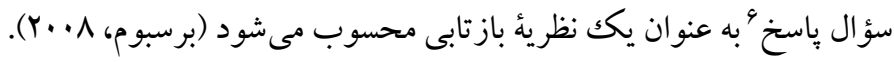

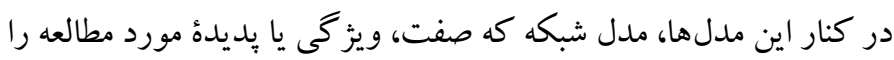

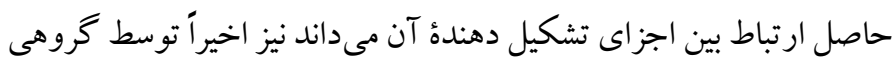

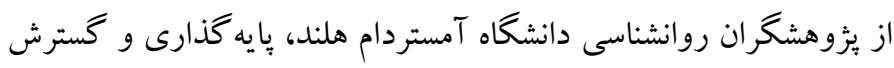

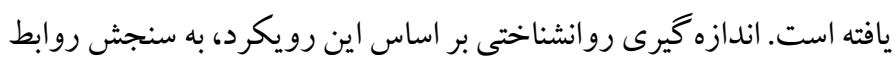

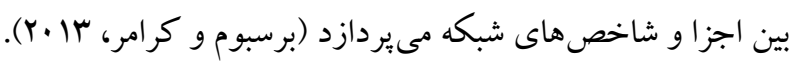

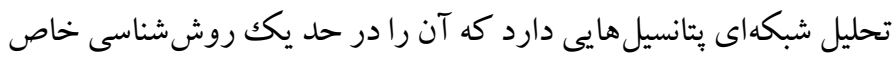

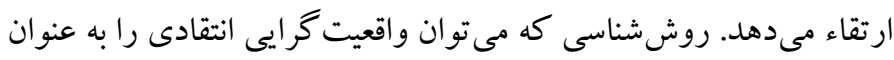

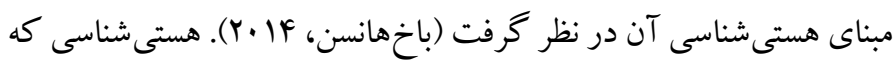

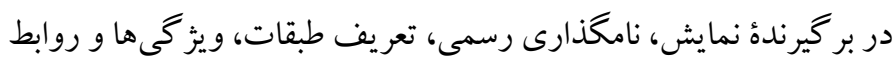

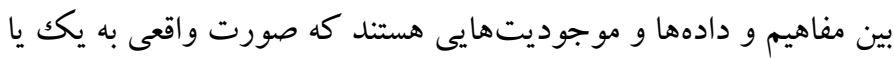

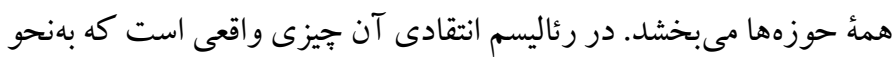
علّى مؤثر باشد (توانا، سوسما).

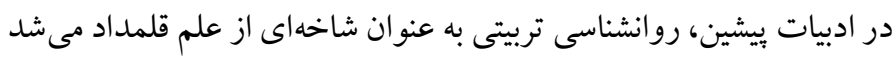

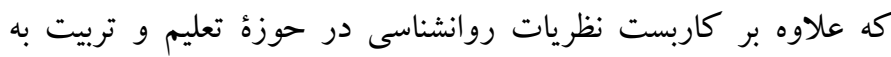

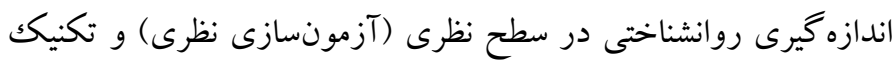

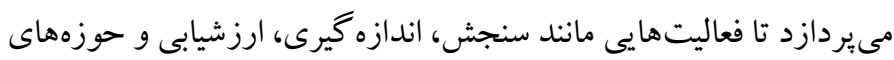

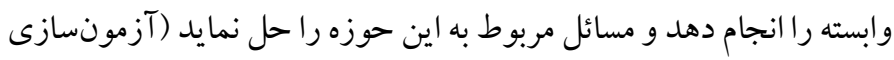

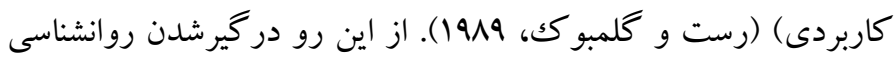

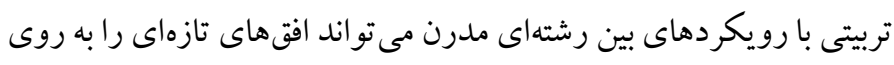

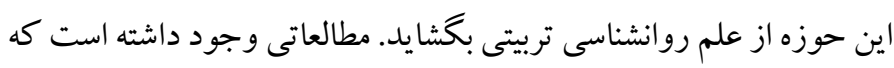

1. testing

2 . empirical

3 . reflective interpret

4 . formative interpret 
كر ههاى شبكه همان سؤالات آزمون مورد مطالعه خو اهند بود و ارتباط بين

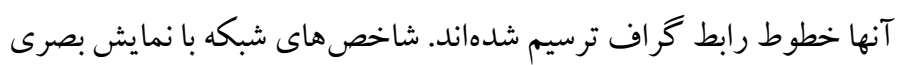

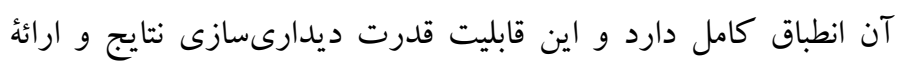
كزارشهاى ساده و در عين حال جامعى از تحليل آزمونسازى سؤالات

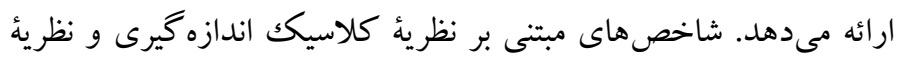

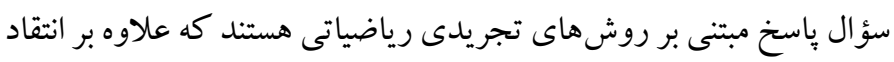

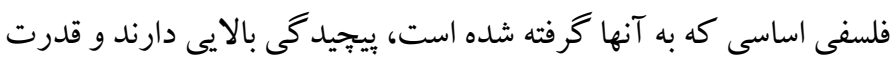

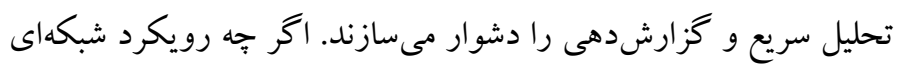

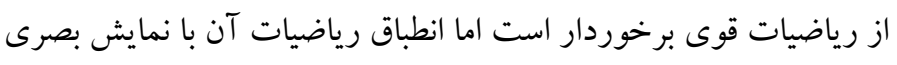
شبكه، امكان دركك درست رياضيات را به همراه دارد (سرين، كاتر و

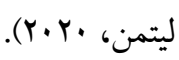

در اينجا از مزاياى تحليل دادههاى شبكهاى در جهت تحليل سؤالات

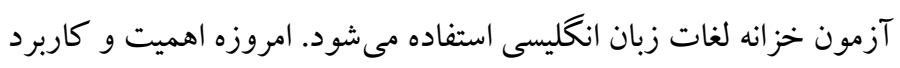
زبان انگليسى در امور شغلى و تحصيلى در عرصهُ بين الملل بر هيج كس أنس يوشيده نيست. با توجه به نيازهاى متخصصين حوزههاى مختلف به به ابزار

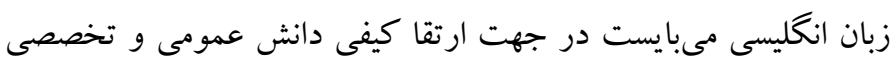

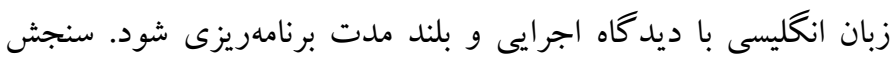

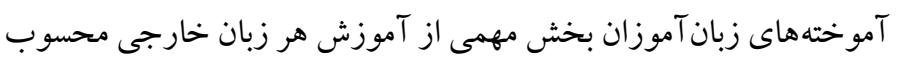

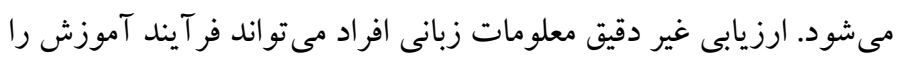

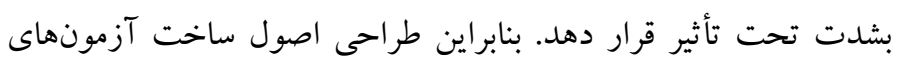

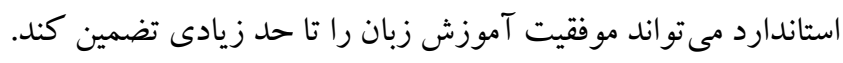
معرفى تحليل دادههاى شبكهاى به عنوان يكك روش در گسترش مفاهيم

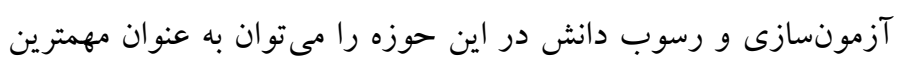

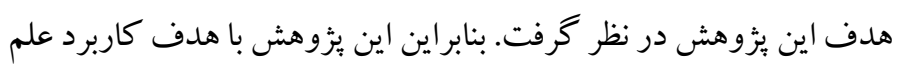

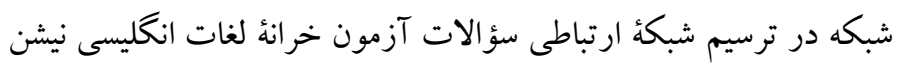

$$
\text { و وارينگ (199V) انجام شد. }
$$

الف) طرح ئزوهش و شر كت كنند كان: اين يثوهش تحليلى - توصيفى

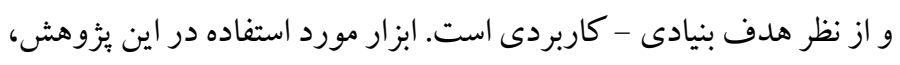
آزمون خزانه لغات انگليسى نيشن و وارينگك (199V) مىباشد و تمركز

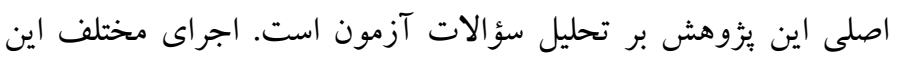

تحليل شبكه در حوزهٌ روانشناسى و اندازهيرى روانى مىتواند تلاش

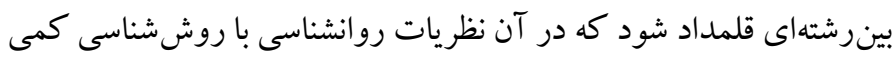

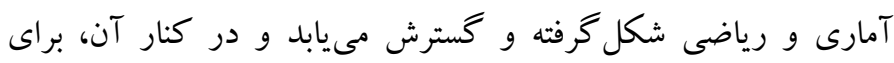

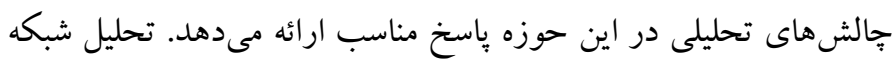

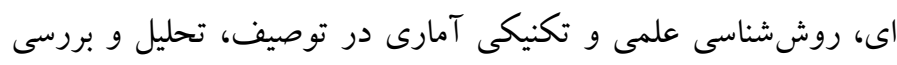

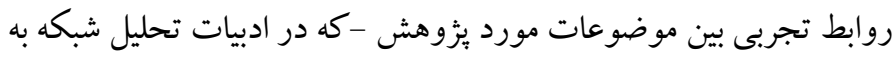

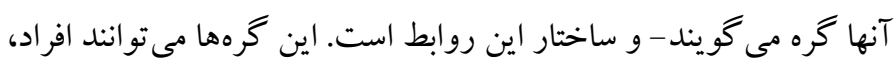

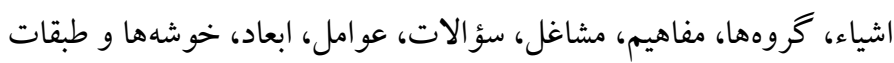

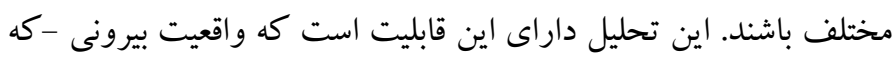
به صورت شبكه است- را به طور منظم و فشرده تشريح كند و امكان اندان

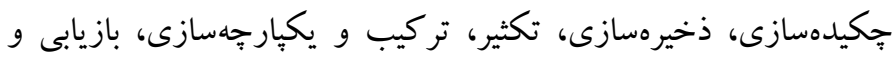

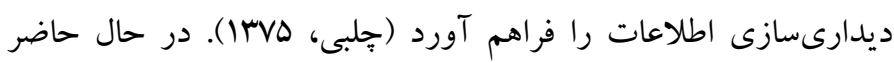

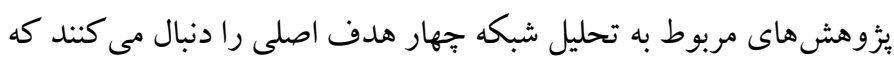

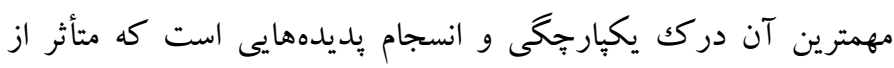

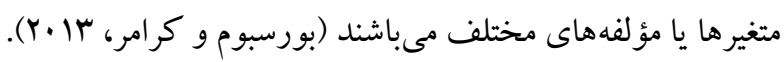

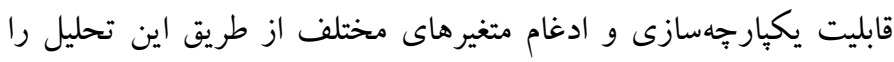

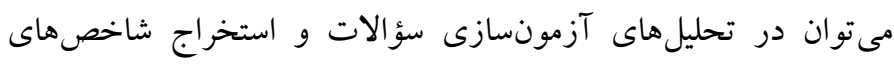

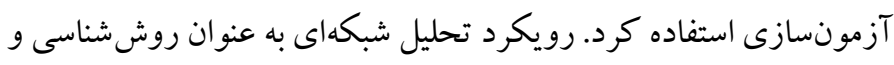

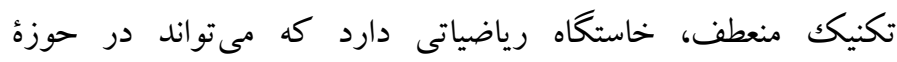

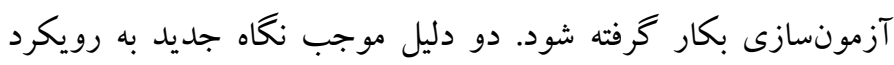

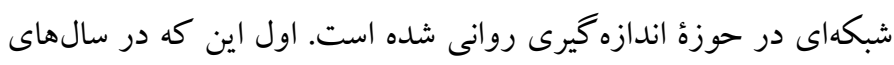
اخير مدلها و نظريات مربوط به متغيرهاى ينهان سيطره داشتهاند و دوم اين اين

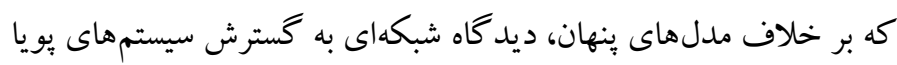
كمك كرده است. گسترد گى سيستمهاى يويا از لحاظ محتو ايى بسيار زياد

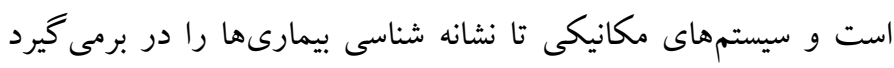

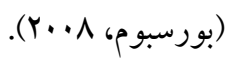
هدف تحليل سؤال و تعيين شاخصهاى آزمونسازى سؤالات، شناسايى

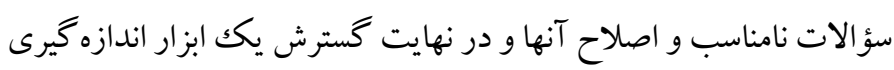
است. در ساير روشهاى تحليل سؤال دستيابى به اين هدف با مشخص -

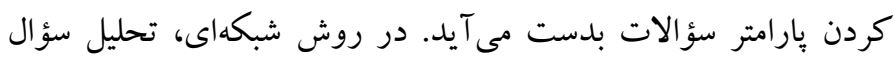

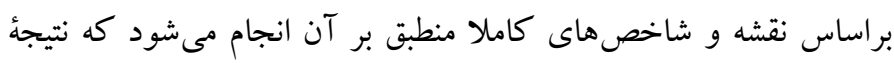

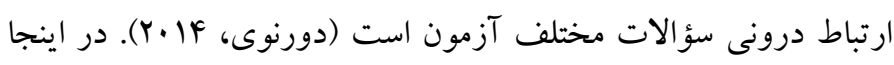


دارد كه در انتخاب بزظوهشكر بى تأثير نبوده كه از آن جمله مى توان به موارد

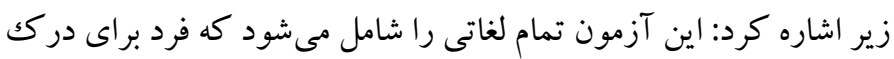

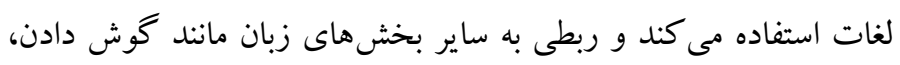

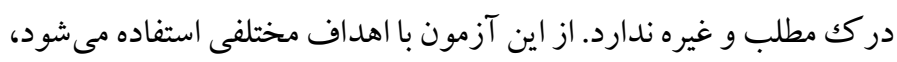
مثلا براى تدوين برنامهريزى و طر احى درسى، براى سنجش قبل از ورود به به إنه

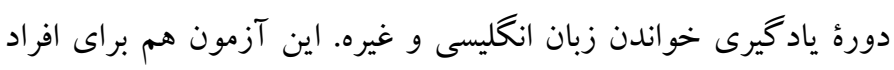
انگليسى زبان و هم براى افرادى كه انخليسى زبان دوم آنها است، استفاده

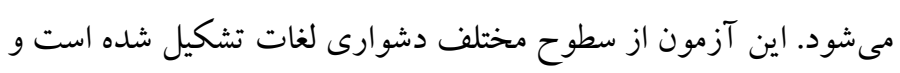

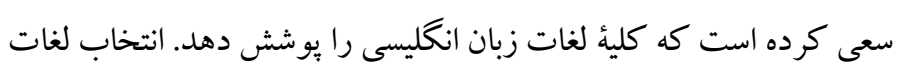
در اين آزمون بر اساس خانواده لغاتى هستند كه از بيكرة ملى بريتانيايى ' (BNC) بخشهاى مختلف ملل انغليسى زبان وجود دارد. مجموعه لغات BNC شش سطح مختلف دارد كه در اين آزمون همخى سطوح وجود دارند. در

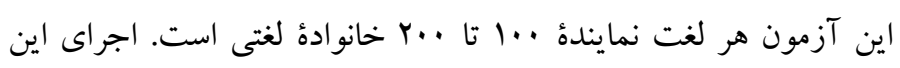
آزمون مى تواند براى زبان آموزان در سطوح مختلف تسلط استفاده شود. اين آزمون جيزى را مىسنجد كه فرض سنجش آن وجود دارد، بگلار

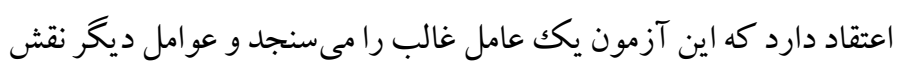

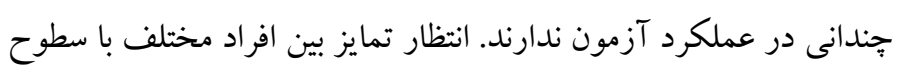
مختلف زبانى بر اساس اين آزمون بر آورده مىشود و قدرت بالايى در تمايز

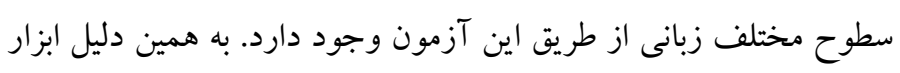

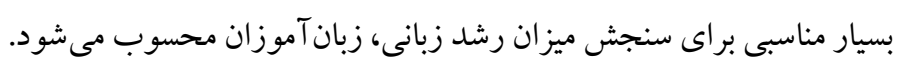

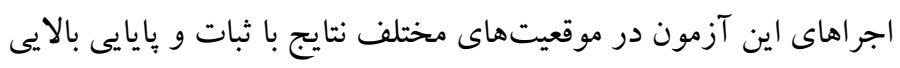

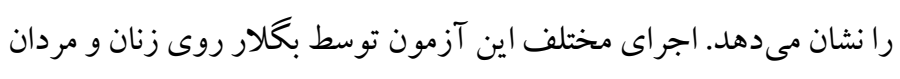
با سطوح مختلف توانايى زبانى به مقادير بايايى بالايى منجر شده است

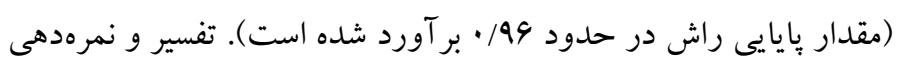
آزمون آسان و بصورت دو ارزشى (غلط يا صحيح) مىباشد، سؤالات

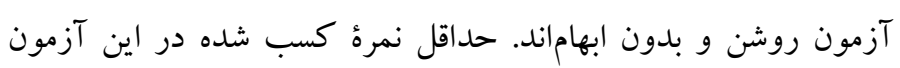

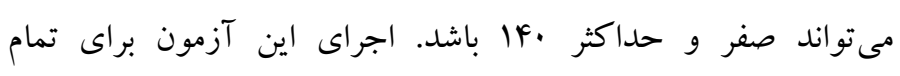

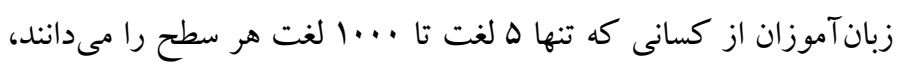

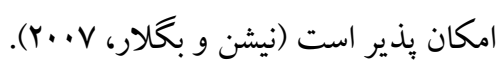

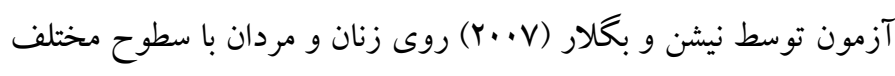

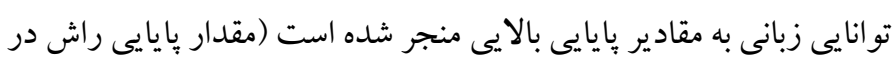

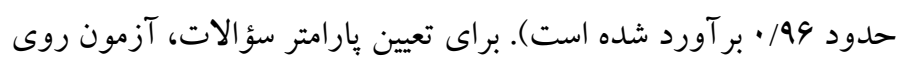

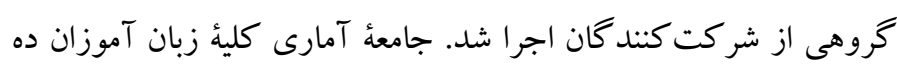

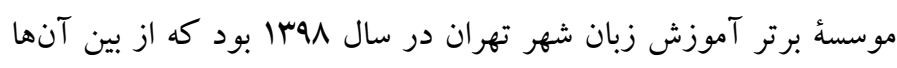
1009 ازبان آموز به روش نمونه گيرى در دسترس انتخاب شدند و به آزمون

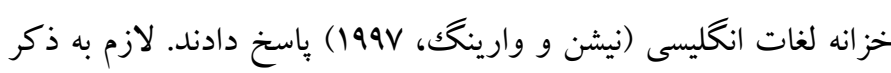

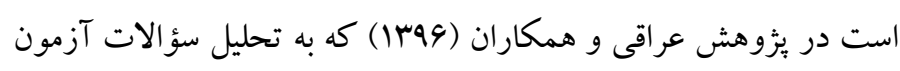

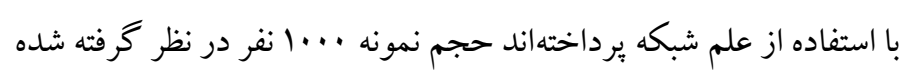

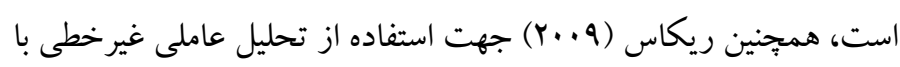

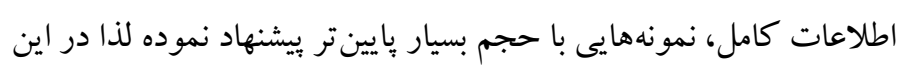

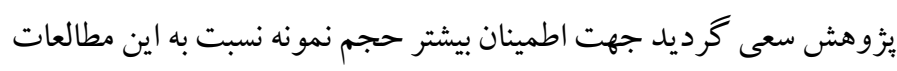

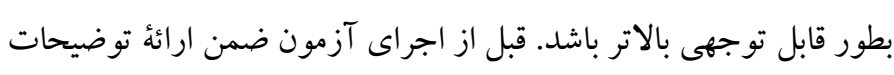

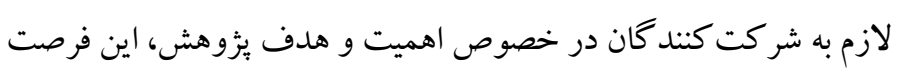

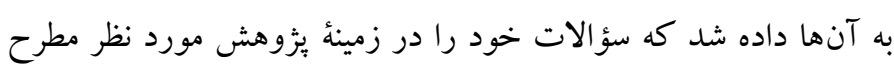

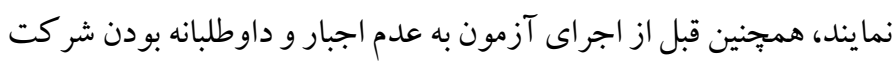

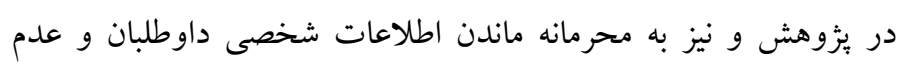
استفاده از اين اطلاعات در جاى ديخر، اشاره شد و به منظور جلب أبر اعتماد

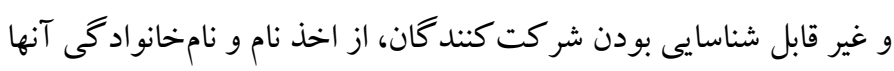

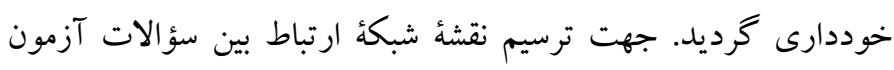

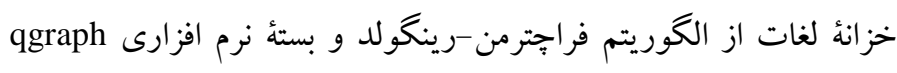
تحت نرمافزار R استفاده شد و بر اساس آن شاخصهاى شبكه استخراج كرديد. جهت بررسى رابطة والد -فرزندى سؤالات شبكه بيز بر اساس

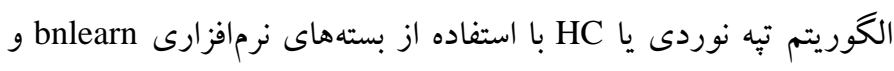
bnviewer

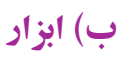
در اين مطالعه تأكيد بر روش شناسى و تكنيك است كه به عنوان نمونه از آزمون ·fl أسؤ الى خزانه لغات انخليسى كه توسط نيشن و وارينگك (199V)

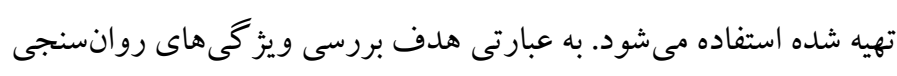

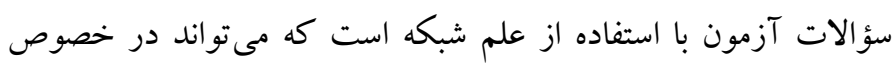

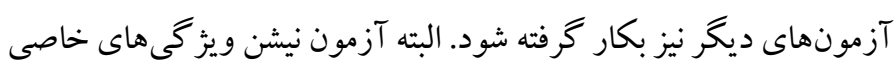

${ }^{1}$. British National Corpus 
1. استفاده از تحليل عاملى به شيوههاى سنتى مستلزم بيوسته بودن نمرات

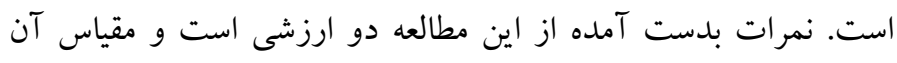
حداكثر رتبهاى است. r. رابطة ابعاد با نمرات در تحليل عاملى سنتى خطى فرض مى شود. در

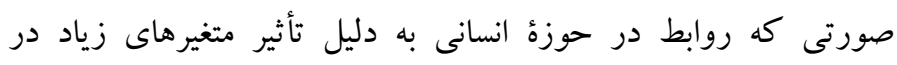
باسخدهى خطى نيست. r. در تحليل عاملى سنتى از كلئ اطلاعاتى كه از يرسشنامه بدست مي لي آيد، استفاده نمى شود. اين عوامل سبب مى شود تا نتوان به روايى آمارى نتايج بدست آمده از

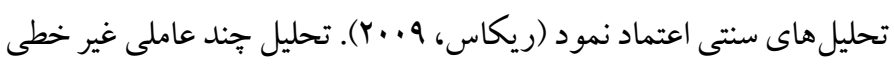

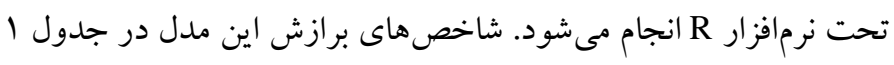
نشان داده شده است.

\begin{tabular}{|c|c|}
\hline مقدار معنادارى & شاخص تناسب \\
\hline$-1.9 \vee \wedge r .9$ & لكاريتم بيشينه درستنمايى \\
\hline rIFIYV.q & اطلاعات آكائيكه \\
\hline rIDG.r & اطلاعات بيزى \\
\hline YIFYAF.F & اصلاح شده اطلاعات آكائيكه \\
\hline rIFVIT.D & اصلاح شدة اطلاعات بيزى \\
\hline p.value $=1$ ।qYVrA.r & $\mathrm{G} 2(1 \mathrm{e}+10)$ \\
\hline$\cdot$ & ريشٔ خطاى مجذور ميانگين \\
\hline
\end{tabular}

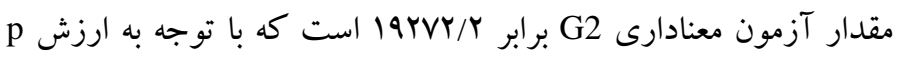

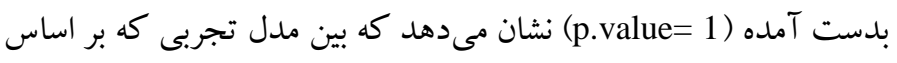

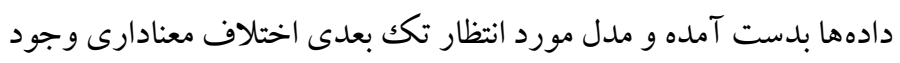

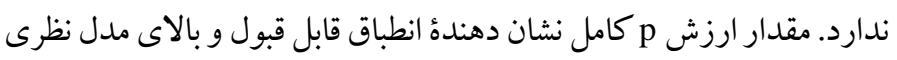
و مدل تجربى است. مقدار ريشه خطاى مجذور ميانگين (RMSEA=0)

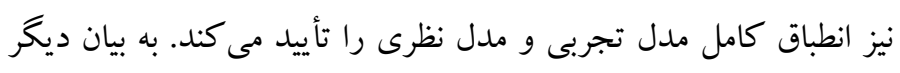
شاخصهاى برازش نشان مىدهند كه مدل تكك عاملى براى اين دادهها

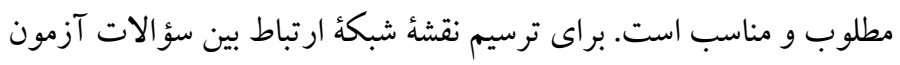
حجم لغات به ماتريس همبستخى نياز داريم. از آنجايى كه سؤالات آزمون دو ارزشى هستند ماتريس همبستخى تتراكوريكك براى اين كار انتخاب

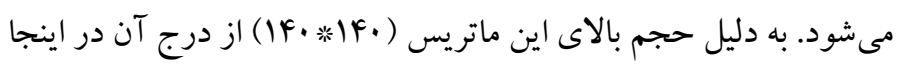
خوددارى مىشود.
يافته ها

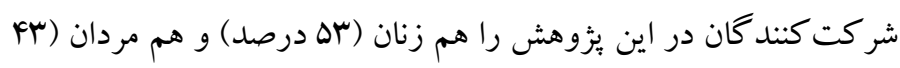

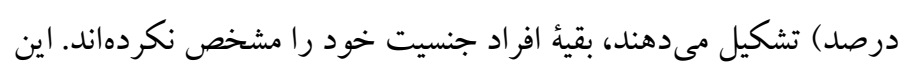

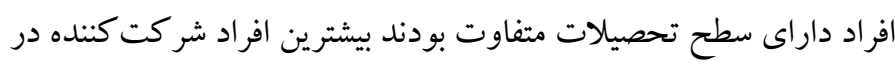
اين بثوهش داراى تحصيلات كارشناسىارشد (MF درصد) و كارشناسى

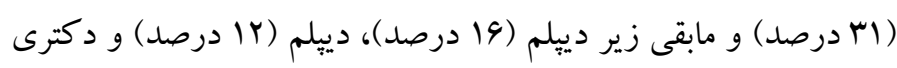

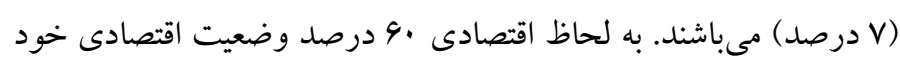
را متوسط، · · درصد خوب، 9 درصد فقير و يكك درصد مرفه قلمداد

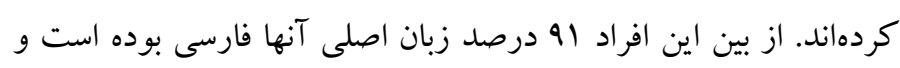

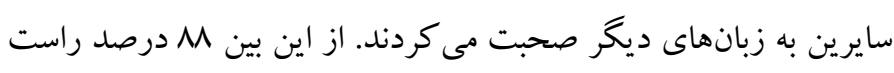

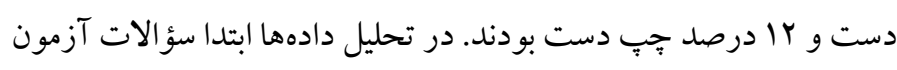

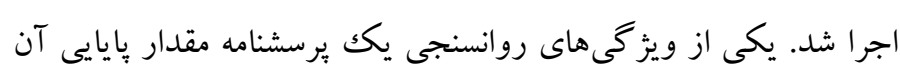

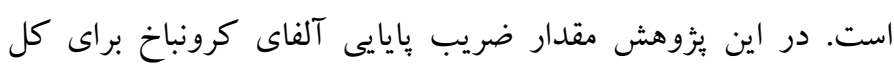

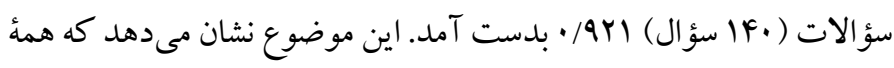

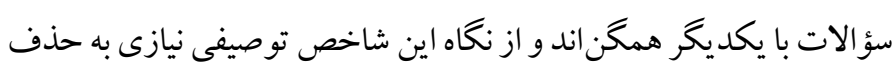

$$
\text { هيج يكك از سؤالات نيست. }
$$

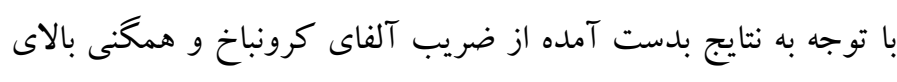

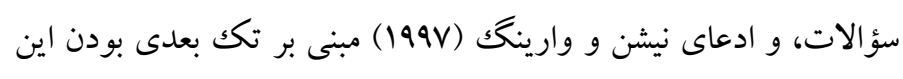

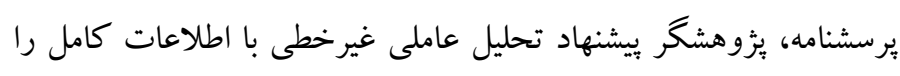

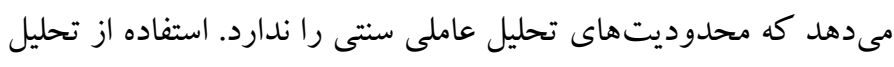
عاملى غير خطى با اطلاعات كامل از لحاظ روانسنجى به منظور آزمونسازى در حوزه علوم انسانى و علوم رفتارى مناسبتر و و دقيقتر مىباشد و انطباق بيشترى با ماهيت موضوعات مربوط به انسان دارد. به بيان

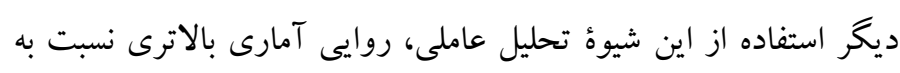
شيوههاى سنتى تحليل عاملى دارد. شيوهاى كنونى (سنتى) تحليل عاملى خطى به فهم مفاهيم زيربنايى و كشف ابعاد (يا سازههاى اصلى) سؤالات

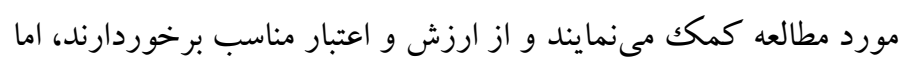
داراى محدوديتهايى نيز مىباشند كه اين محدوديتها ممكن است مانع

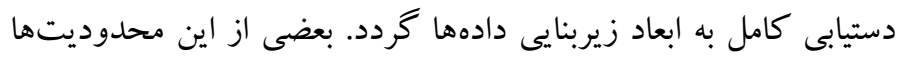

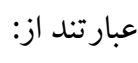


همانطور كه همبستخىهاى سادة تتراكوريك نشان مى دهد، شبكة

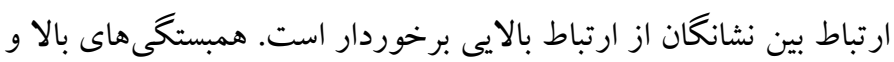

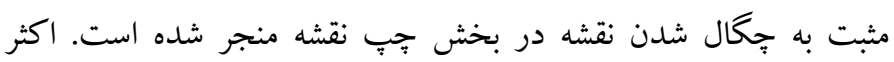

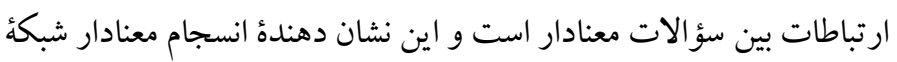

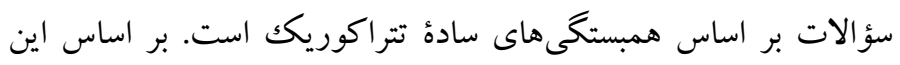

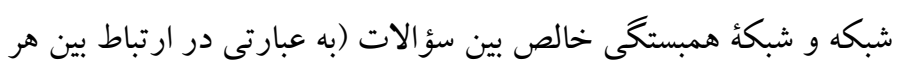

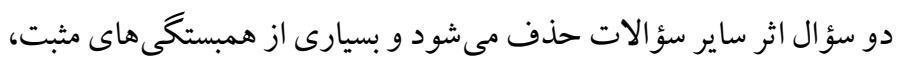

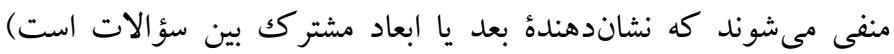
شاخصهاى مر كزيت شبكه بدست مى آيد.

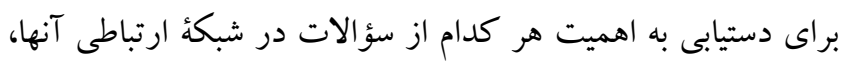
نياز است تا از شاخصهاى مركزيت شبكه استفاده شود. در اينجا جهار

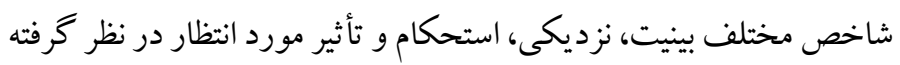

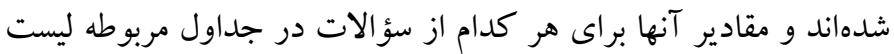
شدهاند. شاخص بينيت به اهميت ارتباطى يك گرهه و نقش آن در ارتباط بين

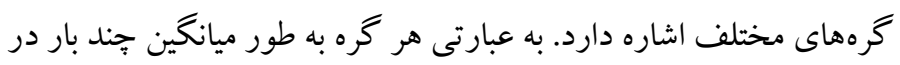

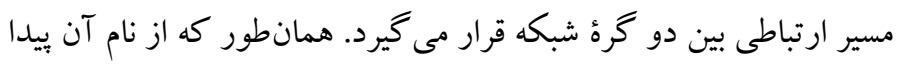

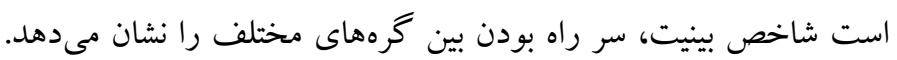

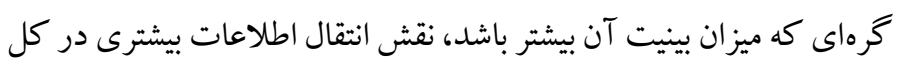

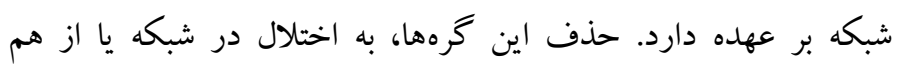

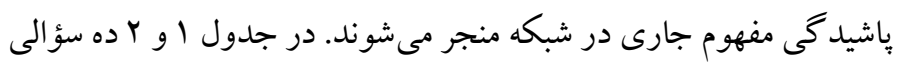
كه بيشترين و كمترين مقدار بينيت را دارند، ارائه شده است.

\begin{tabular}{|c|c|c|}
\hline بينيت & شماره سؤالات & رتبه \\
\hline $1 . r$ & $q 111$ & رتبه | \\
\hline 19 & $q^{r q}$ & رتبه r \\
\hline$\wedge F$ & qre & رتبه \\
\hline$\wedge r$ & q94 & رتبه F \\
\hline Nr & $q 99$ & رتبه هـ \\
\hline $\mathrm{v \wedge}$ & q $q q$ & رتبه 9 \\
\hline V9 & qrr & رتبه V \\
\hline Vq & qirr & رتبه 1 \\
\hline VD & qirr & رتبه 9 \\
\hline Vr & $q \mid r$ & رتبه .1 \\
\hline
\end{tabular}

نقشئ شبكة ارتباط بين سؤالات آزمون حجم لغات براساس الكوريتم

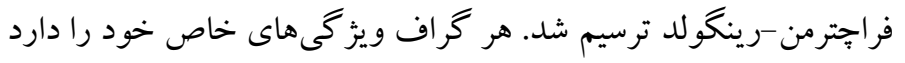
كه به آنها برداخته خواهد شد ترند. الف. ضخامت يالها (منظور خطوط ترسيم شده بين دو كره) نشان دهندة آناء

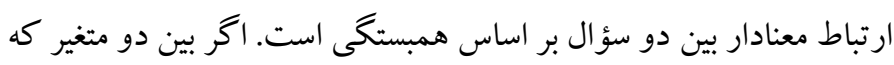

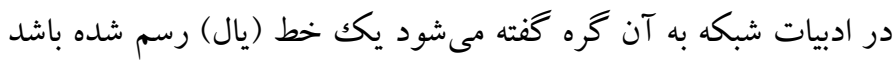

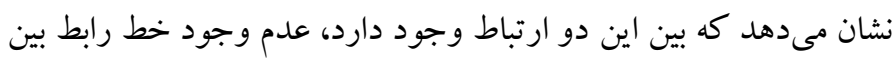
دو متغير نشان دهندة فقدان ارتباط معنادار بين آنها است.

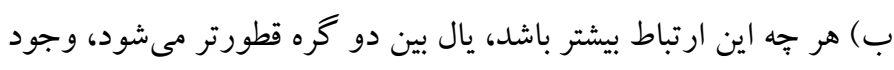

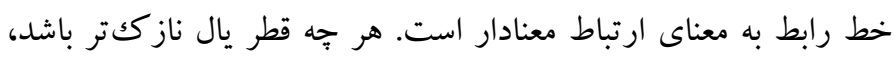

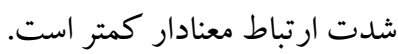

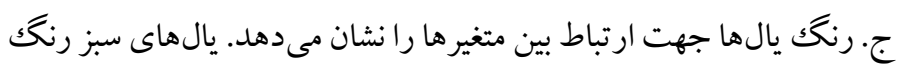

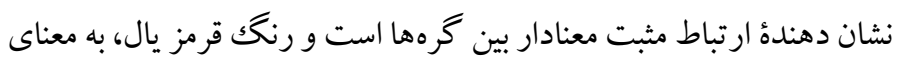
ارتباط منفى معنادار است.

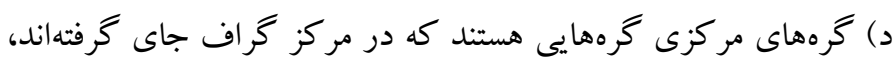

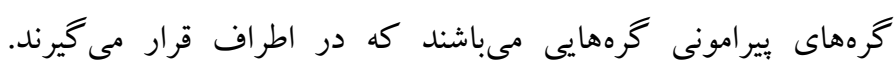

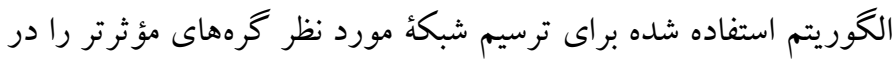

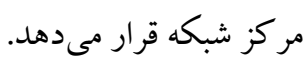

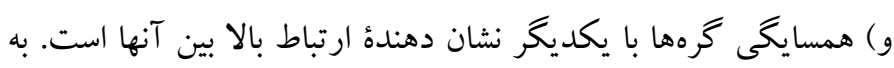

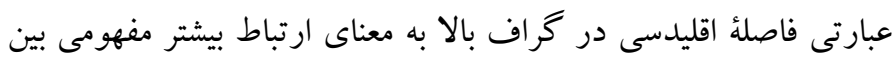

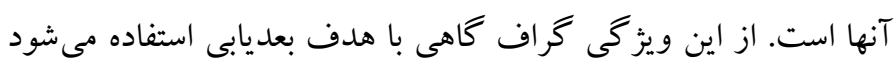

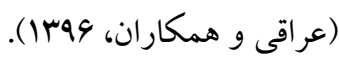

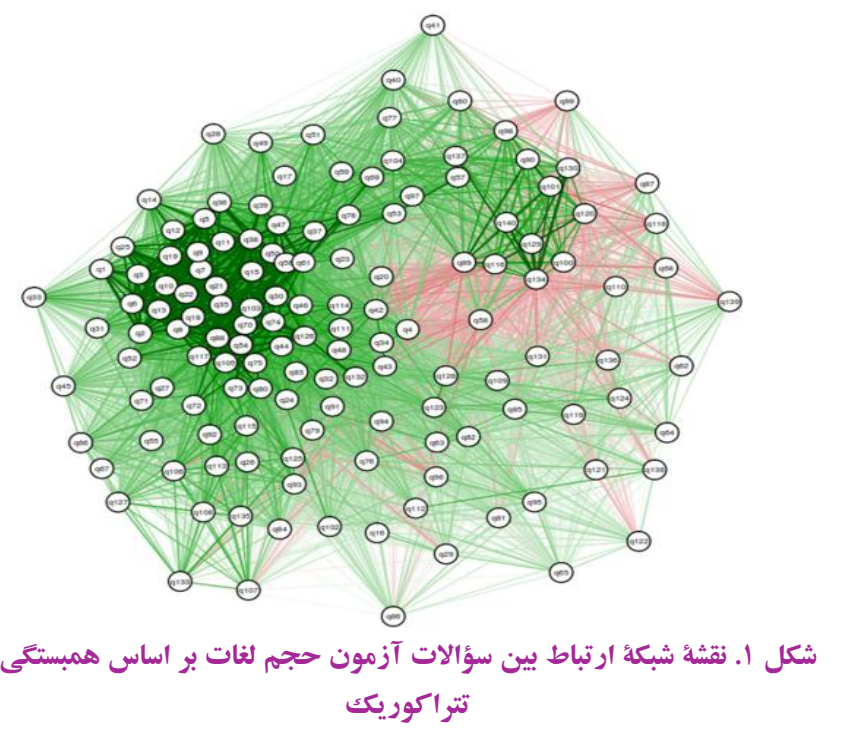


مى سنجند. به عبارت ديخر راه بهينهُ دستيابى به مغهوم ارائه شده توسط كل سؤالات، سؤالاتى هستند كه مقدار نزديكى بالاترى دارند.

\begin{tabular}{|c|c|c|}
\hline نزديكى & شماره سؤالات & رتبه \\
\hline.$/ .194 \Delta \Delta$ & $q 111$ & رتبه | \\
\hline$\cdot / . / q \mu \cdot \Delta$ & q99 & رتبه r \\
\hline.$/ \cdot 1 q \cdot k V$ & qrv & رتبه r \\
\hline$\cdot / \cdot$ /Q.rr & $q 91$ & رتبه F \\
\hline$\cdot / \cdot 1 \wedge 9 \Delta 9$ & $q \& q$ & رتبه هـ \\
\hline$\cdot /$. MAYG & qITr & رتبه 4 \\
\hline$\cdot / \cdot \mid M \Lambda \cdot 1$ & qur & Vتبه V v \\
\hline$\cdot /$. IAVQA & qra & رتبه 1 \\
\hline$\cdot / \cdot \cdot \Lambda$ VVAF & $q \notin V$ & رتبه 9 \\
\hline$\cdot / \cdot \cdot \wedge W \wedge$ & $q+1$ & رتبه ·1 \\
\hline
\end{tabular}

\begin{tabular}{|c|c|c|}
\hline نزديكى & شماره سؤ الات & رتبه \\
\hline •. . IVYMA & qra & رتبه آ|| \\
\hline.$/ \cdot 1 V 19$ & qq & رتبه Yr| \\
\hline.$/$ IVIFF & qro & رتبه سٓו \\
\hline . . IVIFr & qIYF & رتبه IMF \\
\hline $.1 .1994 \mathrm{~V}$ & qrr & رتبه هr| \\
\hline$\%$. VYq & q & رتبه 4س| \\
\hline.$/ .191 Y \Delta$ & $q \wedge$ & رتبه IrV \\
\hline$\cdot / \cdot \mid \Delta \wedge Y F$ & qri & رتبه \\
\hline$\cdot / \cdot \mid \Delta \wedge Y F$ & q9 & رتبه qسا \\
\hline$\cdot / \cdot \mid \Delta \wedge r$ & $q \mu \wedge$ & رتبه ·ff \\
\hline
\end{tabular}

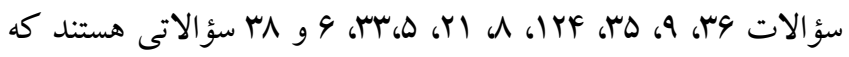
كمترين مقدار نزديكى را دارند. اين سؤ الات از مفهوم مشتر كى كه از ساير سؤالات دركك مى شود، جدا افتادهاند. عموما سؤالاتى كه داراى بينيت بالا هستند داراى نزديكى بالا نيز مىباشند و برعكس. در نمودار زير مقدار همبستگى بين اين دو شاخص و ير اكندگى مقادير مربوطه نشان داده شده
سؤالات ذكر شده در بالا سؤالات مركزىتر در شبكهُ سؤالات حجم لغات زبان انخليسى مىباشند. به عبارتى حذف اين سؤالات بيشترين آسيب را بر انسجام درونى شبكة سؤالات مى گذارد. از آنجايى كه هر سؤال يكك لغت را مى برسد، لغات داراى بالاترين بينيت مىتواند مسير ياد گيرى كل شبكة لغات را نيز نشان دهند. به عبارت ديخر ده سؤالى كه مى توانند به خزانه لغات بيشتر كمكك نمايند، و ارتباط بين آنها را تبين نمايند در ليست بالا مشاهده مىشود.

\begin{tabular}{|c|c|c|}
\hline بينيت & شماره سؤالات & رتبه \\
\hline ro & qrv & رتبه اس| \\
\hline ro & q1.9 & رتبه Yr| \\
\hline YF & qiv & رتبه سٓ| \\
\hline YF & qIYF & رتبه IFF \\
\hline rr & $q \Delta$ & رتبه هr| \\
\hline r. & qro & رتبه وس| \\
\hline$\wedge$ & $\mathrm{q} \Lambda$ & رتبه IrV \\
\hline v & qrı & رتبه NKI \\
\hline$\Delta$ & q9 & رتبه qج| \\
\hline F & qri & رتبه . If \\
\hline
\end{tabular}

گرههاى جدول ب در شبكه سؤالات، گرهماى بيرامونى محسوب مىشوند و از مركز شبكه دور هستند. به عبارتى حذف اين سؤالات تأثير

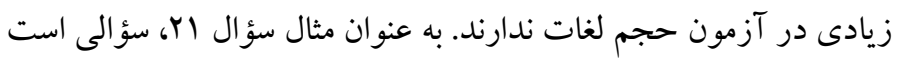

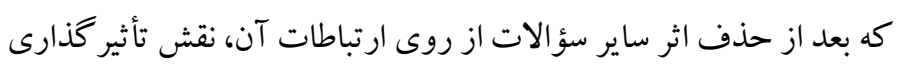
در آزمون خزانه لغات نسبت به ساير سؤالات ندارد.

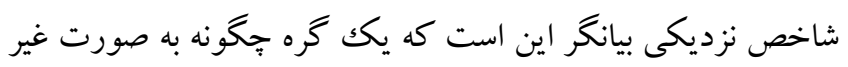

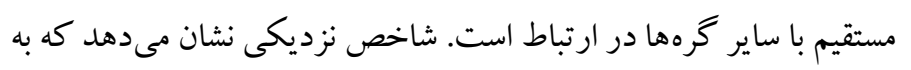

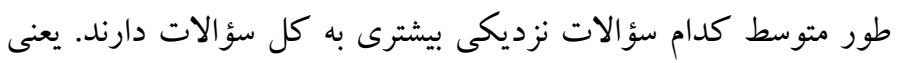

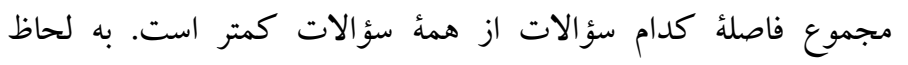
رياضياتى، ميانخين كو تاهترين مسير هر سؤال از ساير سؤالات است. سؤالات سؤال با مقدار نزديكى بالا مىباشند. اين ده سؤال مىتوانند نمايند كان

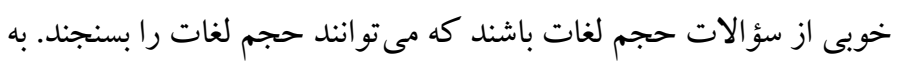

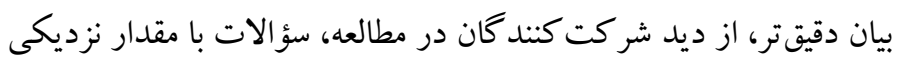
بالاتر، نمايندكان خوبى براى مفهومى هستند كه ساير همد سؤ الات 


\begin{tabular}{|c|c|c|}
\hline استحكام & شماره سؤالات & رتبه \\
\hline rD/YVF. I & qro & رتبه اس| \\
\hline rD/YIFGG & qir. & رتبه זrا \\
\hline YF/GFYQG & qrr & رتبه سחו \\
\hline$r F / \Delta .1 q T$ & qr & رتبه \\
\hline Yr/VYI.V & $q 9$ & رتبه هr| \\
\hline YY/IAYVA & qD & رتبه צسا \\
\hline $\mathrm{r} / \mathrm{MM1} .9$ & $\mathrm{q} \Lambda$ & رتبه IrV \\
\hline r T/GATा & qru & رتبه یז| \\
\hline rI/QNaYF & q9 & رتبه هس| \\
\hline rI/TAG & qri & رتبه . Ff \\
\hline
\end{tabular}

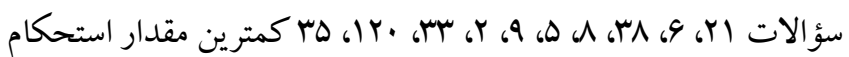

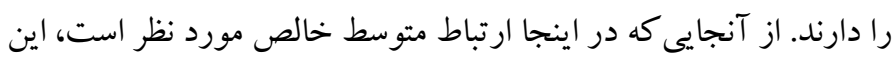
سؤالات ارتباط مستقيم ضعيف با ساير سؤالات دارند.

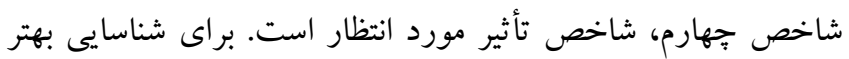

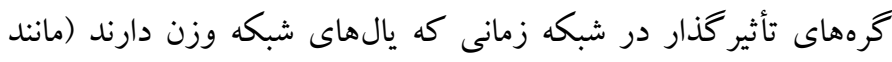
شبكة موجود در اين بزوهش)، لازم است تا بين يالهاى مثبت و منفى تمايز

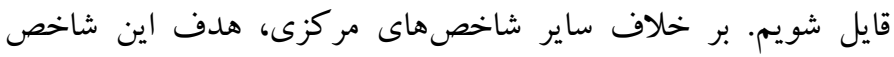
سنجش ماهيت و قدرت كلى و تأثير تجمعى (cumulative influence)

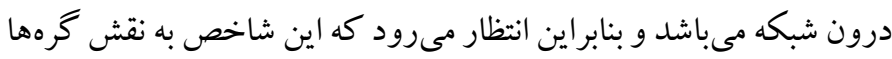

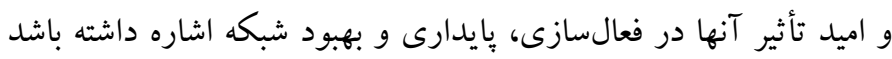

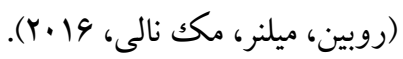

\begin{tabular}{|c|c|c|}
\hline تأثير مورد انتظار & شماره سؤ الات & رتبه \\
\hline F/ATVFAYGY & 990 & رتبه | \\
\hline F/FAY.QYTG & $q 1.9$ & رتبه r \\
\hline F/F১৭৭४イ৭৭ & q94 & رتبه r \\
\hline F/MTGFFIAV & $q 1.9$ & رتبه F \\
\hline F/TGNGOVIT & $\mathrm{q} \Delta \varphi$ & رتبه ه \\
\hline$F / 11919 Y M$ & qri & رتبه 9 \\
\hline$r / q \cdot 1 \% M M \mid \Delta$ & $q \Delta$. & رتبه V v \\
\hline r/AV. \&grqA & qre & رتبه ^ \\
\hline r/virirgn & $q \Delta v$ & رتبه 9 \\
\hline$r / \Delta F \cdot g l r \mid r$ & qra & رتبه .1 \\
\hline
\end{tabular}

$\operatorname{cor}=0.78$

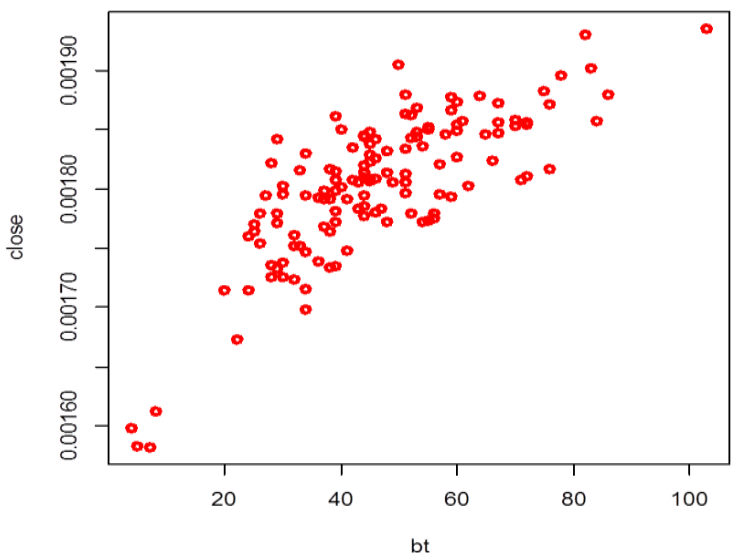

شكل r. مقدار همبستعى بين شاخص نزديكى و بينيت و ير اكندكى مقادير شاخص ديخرى به نام استحكام وجود دارد كه به قدرت ارتباط مستقيم

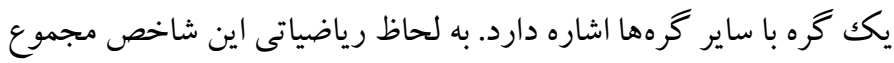

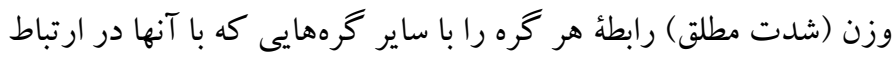
است مشخص مى كند.

\begin{tabular}{|c|c|c|}
\hline استحكام & شماره سؤالات & رتبه \\
\hline r./VYATG & $q 111$ & رتبه 1 \\
\hline$r . / 9191 \mathrm{~V}$ & q $k q$ & رتبه r \\
\hline$r \cdot / \kappa \cdot v \mu_{1}$ & $q 110$ & رتبه r \\
\hline r./MGYIG & qq. & رتبه F \\
\hline$r \cdot / r Y \Delta \Lambda S$ & $q|r|$ & رتبه هـ \\
\hline$r \cdot / . q F V q$ & qrr & رتبه 9 \\
\hline$r .1 .9 \mathrm{VIr}$ & q11 & رتبه V \\
\hline rQ/QVFFq & qrv & رتبه 1 \\
\hline YQ/VTDFA & qer & رتبه 9 \\
\hline$r ৭ / 9 \Delta \Delta \Delta \Lambda$ & $q^{+1}$ & رتبه ·1 \\
\hline
\end{tabular}

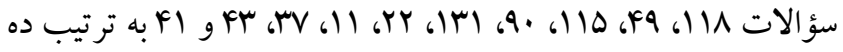
سؤ الى هستند كه بيشترين مقدار استحكام را دارند. به عبارتى ارتباط مستقيم

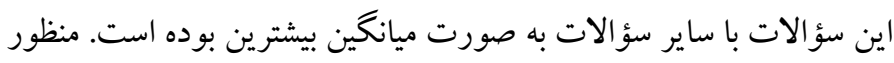

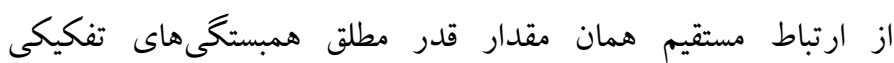
تتراكوريكك است. در اينجا تعداد ارتباطات اهميت ندارد. 
عبارتى در پايدارى شبكه و فعالسازى شبكه كمترين نقش را نسبت به ساير

$$
\text { سؤالات دارند. }
$$

نقشُ شبكهُ بيزى سؤالات به صورت كلى بر اساس الكوريتم تِه نوردى يا HC با استفاده از بستههاى نرمافزارى bnlearn و bnviewer ترسيم شد. از آنجايى كه اين نقشه ديناميكك است، فضاى كاغذى امكان بررسى دقيق آن را به لحاظ ديدارى، ندارد. در اينجا شبكه، بر اساس قواعد بيزين ترسيم شده است به همين دليل يالها داراى جهت اند و دورى در شبكه مشاهده نمىشود. لازم به ذكر است كه در سؤالات بالا شبكهها بر اساس الكوريتم فراجترمن -رينگگ لد كه غير بيزينى است ترسيم شده بودند تا نقشهُ كلى و اهميت سؤالات در مفهوم خزانه لغات را نشان دهند. شبكة بيز رابطة والد فرزندى سؤالات مختلف را مشخص مى كند. بهعبارتى مشخص مى كند كه والدين هر سؤال جهه سؤال يا سؤالاتى مىباشد. از آنجايى كه قابليت اين تصوير با استفاده از كامييوتر ممكن است در زير بريدهاى از رابطهُ والد فرزندى بعضى از سؤالات نشان داده مى شود.

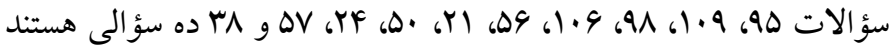
كه بيشترين تأثير كذارى را بر شبكة مورد مطالعه دارند.

\begin{tabular}{|c|c|c|}
\hline تأثير مورد انتظار & شماره سؤالات & رتبه \\
\hline qr. & رتبه اس| & رتبه 1 \\
\hline$q 110$ & رتبه זrا & رتبه r \\
\hline qIro & رتبه سٓו & رتبه r \\
\hline qIrr & رتبه INF & رتبه F \\
\hline qrr & رتبه هr| & رتبه هـ \\
\hline qqF & رتبه وسا & رتبه 9 \\
\hline qra & رتبه IrV & رتبه V V \\
\hline$q \wedge q$ & رتبه رW| & رتبه 1 \\
\hline$q^{k}$. & رتبه وسا & رتبه 9 \\
\hline qro & رتبه · If & رتبه ·1 \\
\hline
\end{tabular}

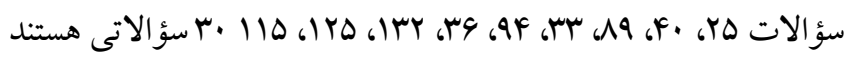
كه كمترين تأثير را بر شبكة سؤالات مؤثر بر آزمون خزانه لغات دارند. به

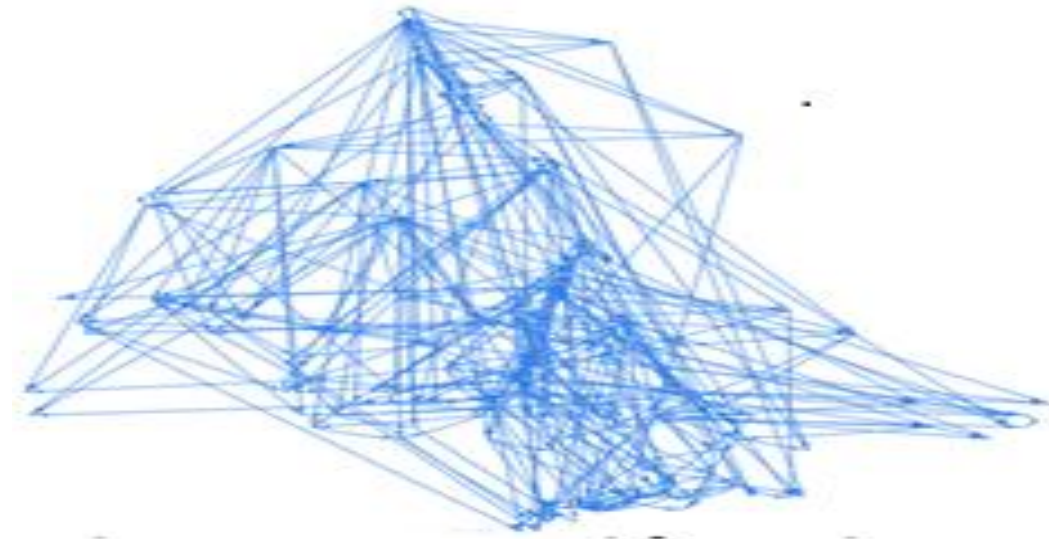

شكل r. شبكه بيزين با الكوريتم HC در ارتباط كلى بين سؤالات آزمون حجم لغات

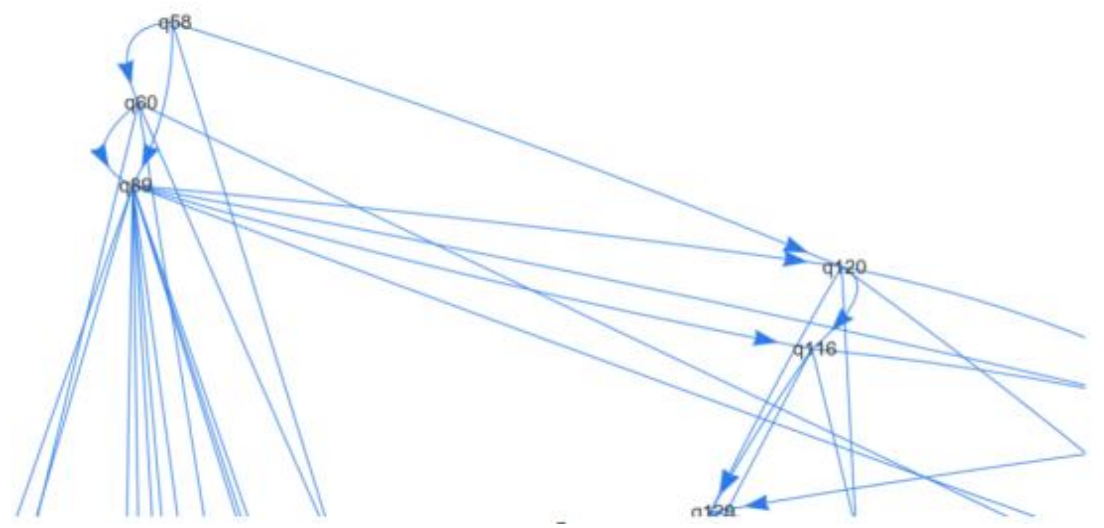

شكل ع. بزركنمايى بخشى از شبكة بيزين ارتباط بين سؤالات آزمون حجم لغات 
متغيرها است. در آزمونهاى روانى سؤالات مختلف آزمون به عنوان متغيرهاى مختلف مىباشند كه شبكة بيزى قابليت شناسايى وابستكى بين

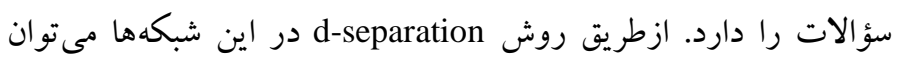
كزارههاى استقلال شرطى را بدست آورد. هر يال در شبكة بيزين ترسيم شده از شدت يكسان برخوردار نيست، هر يال داراى قدرت يات شدرات مشخص است. خطوط بين گرههاى مختلف اطلاعات مناسبى را به منظور تحليل محتواى سؤ الات يرسشنامه ارائه مى دهند. نقشهٔ ارتباطى بين سؤ الات

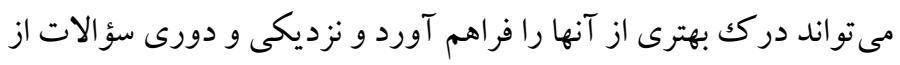
يكديخر را مىتوان به لحاظ محتو ايى بررسى كرد. استفاده از شيوههاى

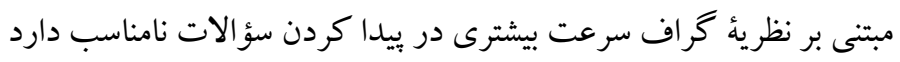

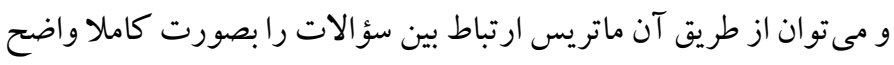
بصرى نمود و اطلاعات زيادى را بصورت يكجا ارائه نمود. از آنجايى كه

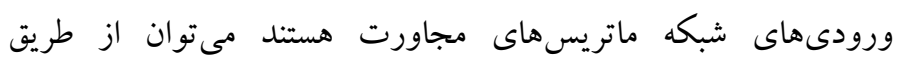
همبستخى هاى تفكيكى و نيمه تفكيكى به در كك درستى از اهميت سؤالات

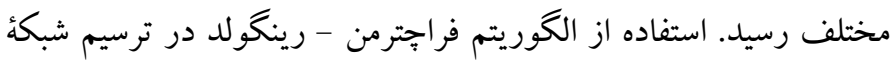

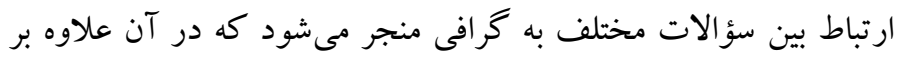
اينكه فو اصل بين سؤالات مختلف معنادار است قطر يالها، ابعاد زيربنايى نقشه، ساختار و خوشههاى تشكيل شده نيز مى توانند در تحليل سؤالات استفاده شوند و امكان بعديابى را حداقل در فضاى دو بعدى فر فراهم آورد. از جمله محدوديتهاى يزٔوهشى مىتوان به كمبود مطالعات يزوهشى در

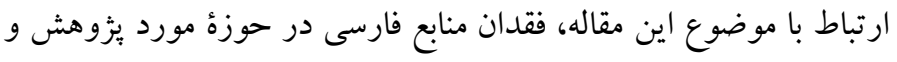

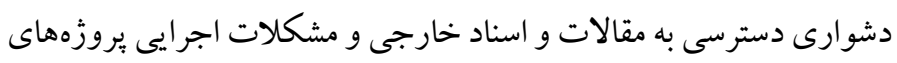

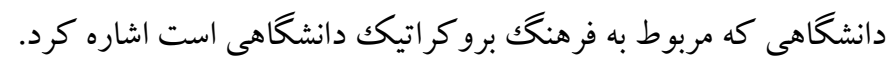

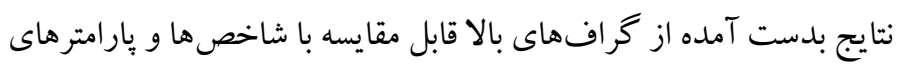

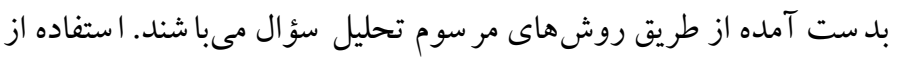

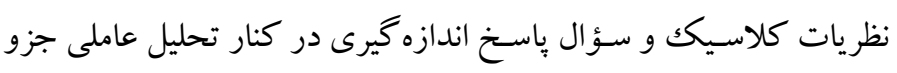
روشهاى مرسـوم تحليل سـؤال به شــمار مىرود. با توجه به مغفول ماندن

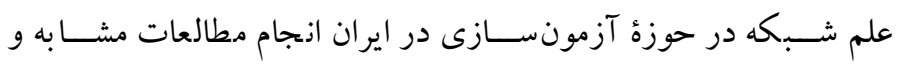

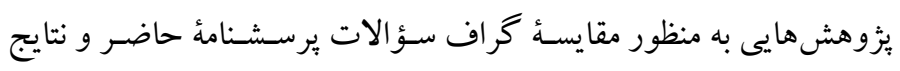

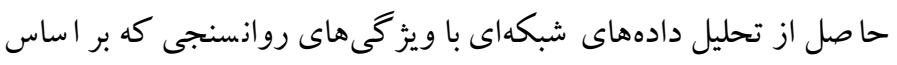
شيوههاى مرسوم و كلاسيك بدست مى آيند بيشنهاد مى شودد.

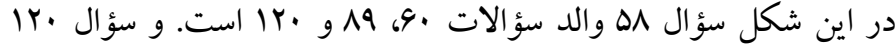
فرزند سؤالات 9 و وه است. در اين مدل والد - فرزندى كلية سؤالات

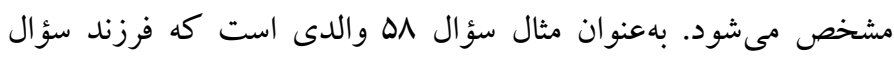

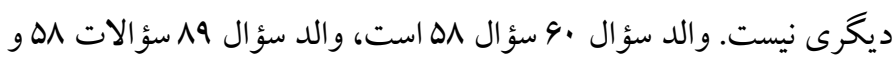

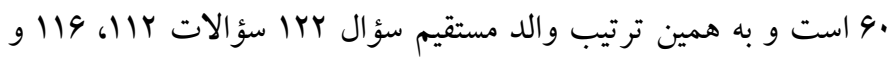

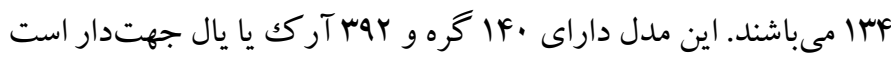
كه با الكوريتم HC بدست آمدهاند. ساير مشخصات مدل در زير ارائه شده

$\begin{array}{ll}\text { nodes: } & 140 \\ \text { arcs: } & 392 \\ \quad \text { undirected arcs: } & 0 \\ \text { directed arcs: } & 392 \\ \text { average markov blanket size: } & 9.37 \\ \text { average neighbourhood size: } & 5.60 \\ \text { average branching factor: } & 2.80 \\ & \\ \text { learning algorithm: } & \text { Hill-Climbing } \\ \text { score: } & \text { BIC (disc.) } \\ \text { penalization coefficient: } & 3.674937 \\ \text { tests used in the learning procedure: } & 1432673 \\ \text { optimized: } & \text { TRUE }\end{array}$

بحث و نتيجه كيرى هدف از يزوهش حاضر كاربرد علم شبكه در ترسيم شبكة ارتباطى سؤ الات

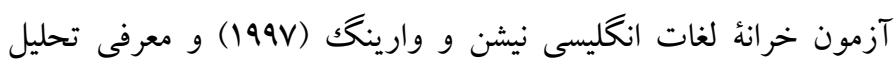

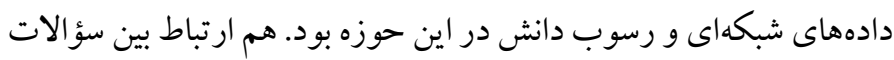
از طريق گراف ارتباطى آنها، نيازمند دانش فنى زياد دربارهُ نظريات

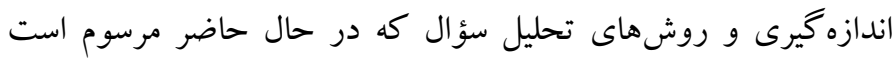

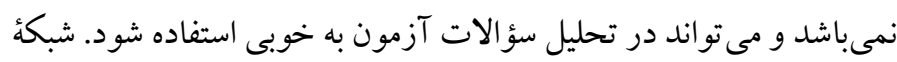

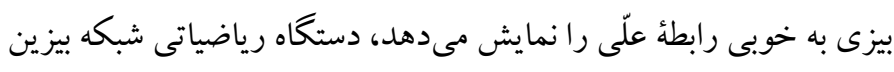

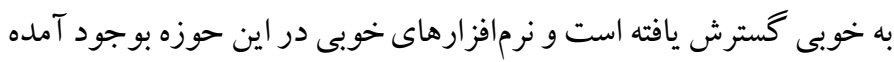

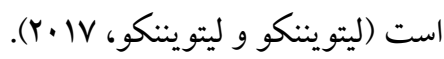
شبكههاى بيزى يكك مدل احتمالاتى كرافيكى است كه مجموعهاى از

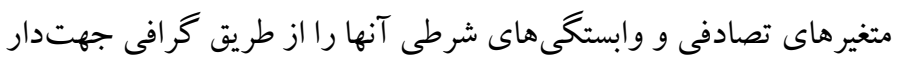

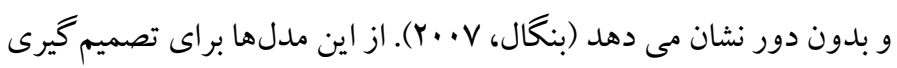

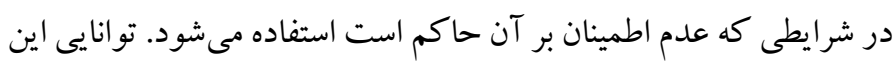

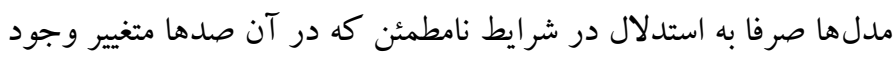
دارد، نيست بلكه براى كمكك به افراد با هدف فهم حوزهُ مورد نظر نيز

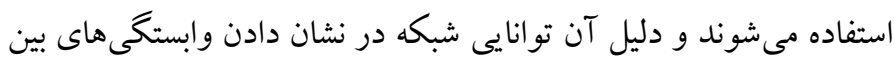


حامى مالى: اين يُزوهش در قالب رساله دكترى و بدون حمايت مالى مىباشد.

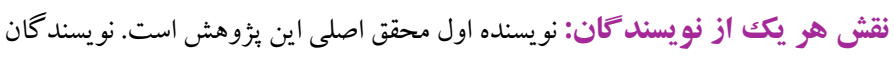
دوم و سوم استادان راهنما و نويسنده جهارم استاد مشاور رساله مىباشند. تضاد منافع: نويسند گان هيج تضاد منافعى در رابطه با اين يُروهش اعلام نمىنمايند.

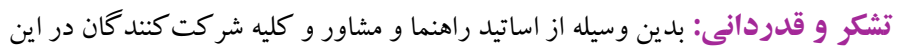
يثزوهش تشكر و قدردانى مى گردد.

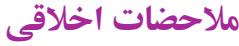

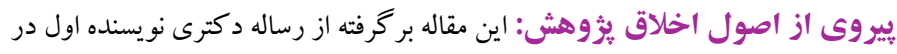

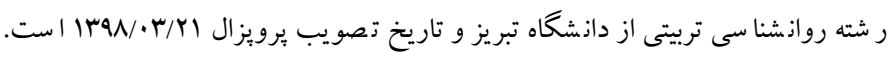

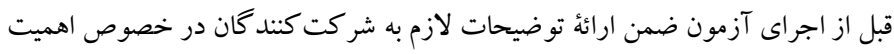

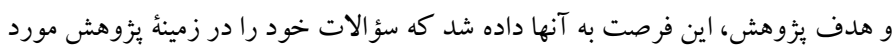

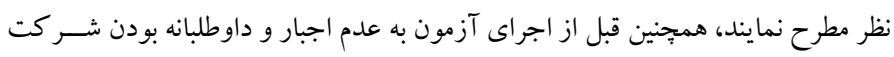
در ئزوهش و نيز به محرمانه ماندن اطلاعات شــخصـى داوطلبان و عدم اســفاده از اين اطلاعات در جاى ديكر، اشـاره شـــ و به منظور جلب اعتماد و غير قابل شــاسـايى بودن شر كت كنند گان، از اخذ نام و نام خانوادگى آنها خوددارى گرديد 


\section{References}

Almond, R. G., \& Mislevy, R. J. Steinberg, L. S., Yan, D., \& Williamson, D. M. (2015). Bayesian Networks in Educational Assessment. Statistics For Social \& Behavioral Sciences. NewYork, NY. DOI: 10.1007/978-1-4939-2125-6. [link]

Araghi, L., Taheri, A., Joz Ramazani, Z., Abas Pour, A., \& Zarghami, M.H. (2017) Study of applying network data analysis in item analysis. Quartery of Educational Measurement. 7(28), 207-240. DOI: 10.22054/jem.2017.2787.1086. [Link]

Ben-Gal, I. (2007) Bayesian networks. In: Ruggeri F, Faltin F, Kenett R (eds) Encyclopedia of statistics in quality \& reliability. Wiley, London. DOI: 10.1002/9780470061572.eqr089. [link]

Borsboom, D. (2008). Psychometric perspectives on diagnostic systems. Journal of Clinical Psychology, 64, 1089-1108. DOI: 10.1002/jclp.20503. [link]

Borsboom, D., \& Cramer, A.Q. (2013). Network Analysis: An Integrative Approach to the structure of Psychpathology. Annual review of Clinical Psychology, 9, 91-121. DOI: 10.1146/annurevclinpsy-050212-185608. [link]

Buch-Hansen, H. (2014). Social network analysis and critical realism. Journal for the Theory of Social Behaviour, 44(3), 306-325. DOI: 10.1111/jtsb.12044. [link]

Chalabi, M. (1995). Network Analysis in Sociology. Journal of Social Science, 3(5-6), 9-48. DOI: 10.22054/qjss.1995.5152. [Link]

Culbertson, M.J. (2015). Bayesian Networks in Educational Assessment: The State of the Field. Applied Psychological Measurement, 40(1) 3-21. DOI: 10.1177/0146621615590401. [link]

Dörnyei, Z. (2014). Researching complex dynamic systems: 'Retrodictive qualitative modelling' in the language classroom. DOI: 10.1017/S0261444811000516. [link]

Epskamp, S., Cramer, A. O. J., Waldrop, L. J., Schmittmann,V. D., \&Borsboom, D. (2012). qgraph: Network visual-izations of relationships in psychometric data. Journal of Statistical Software, 48(4), 1-18. DOI: 10.18637/jss.v048.i04. [link]

Fortunato, S. (2010). Community detection in graphs. Physics Reports, 486(3-5), 75-174. DOI: 10.1016/j.physrep.2009.11.002. [Link]

Litvinenko, A., \& Litvinenko, N. (2017). Application of Bayesian Networks for Estimation of Individual Psychological Characteristics. Przeglad Elektrotechniczny. $1(5) . \quad$ DOI:
10.15199/48.2019.05.23. [Link]

Millán, E., Laboda, T., Pérez-de-la-Cruz, J. L., \& García, F. (2010). Bayesian networks for student model engineering. Computers and Education, Language Teaching, 47(1), 80-91.55(4): 1663-1683. DOI: 10.1016/j.compedu.2010.07.010. [Link]

Nation, I.S.P., Beglar,D. (2007) A Vocabulary Size Test. The Language Teacher, 31(7), 9-13. [Link]

Nation, I.S.P., \& Waring, R. (1997). Vocabulary Size, text coverage and word lists. In N. Schmitt \& M. McCarthy (Eds.), Vocabulary: Description, acquisition and pedagogy (pp. 6-19). Cambridge: Cambridge University Press. DOI:10.4236/ojml.2015.53023. [Link]

Reckase MD (2009). Multidimensional Item Response Theory. Springer-Verlag, New York. DOI:10.1007/978-0-387-89976-3. [Link]

Robinaugh, D. J., Millner, A. J., \& McNally, R. J. (2016). Identifying highly influential nodes in the complicated grief network. Journal of Abnormal Psychology, 125(6), 747-757. DOI: 10.1037/abn0000181. [Link]

Rust, J., Golombok, S. (2009). Modern Psychometrics. The Science of Psychological Assessment, (3rd ed.). New York: Routledge. [Link]

Saarinen, S., Cater, E., Littman, M. L. (2020). Applying prerequisite structure inference to adaptive testing. In Proceedings of the Tenth International Conference on Learning Analytics \& Knowledge (LAK 20). Association for Computing Machinery, New York, NY, USA, 422-427. DOI: 10.1145/3375462.3375541. [Link]

Tavana, M. A. (2015). The Paradigm of Critical Realism Interdisciplinary Methodology. Journal of Interdisciplinary Studies in the Humanities. 7(1), 27-56. DOI: 10.7508/isih.2015.25.002. [Link] 